\title{
Relação entre o solo e a composição florística de remanescentes de vegetação natural no Município de Ribeirão Preto, SP
}

\author{
OLGA KOTCHETKOFF-HENRIQUES ${ }^{1,4}$, CARLOS A. JOLY² e LUÍS C. BERNACCI ${ }^{3}$
}

(recebido: 15 de janeiro de 2004; aceito: 9 de junho de 2005)

\begin{abstract}
Soil and floristic composition of native vegetation remnants relationship in the municipality of Ribeirão Preto, $\mathrm{SP}$ ). Aiming to establish the relationship between soil characteristcs and floristic composition, 95 fragments of natural vegetation were visited, and their floristic composition was determined by the expedite survey method. A total of 509 tree species belonging to 71 botanic families were found. A detrended correspondence analysis (DCA) and a cluster analysis using relative Sørensen distance showed three floristic groups associated with particular soil types. A multi-response permutation procedure (MRPP) indicated the groups consistence. A main group associated with the basalt derived soils, Purple Latosol and Lytholic soil, could be slipt into two subgroups according to the rock desintegration degree: mesophilous and decidous forest, respectively. The other two groups were linked to the Dark Red and Yellow Red Latosol, the cerradão, and to the Hydromorfic Soil, the swamp forest. Each group presented a characteristic floristic composition. Considering the most abundant tree species, meanly $65 \%$ of them showed differential occurrence in the different soil types. A high proportion of species ocurred in few fragments, and each forest remnant presented somewhat regionally rare species. The observed association between soil and remnants floristic composition could contribute to the establishment of criterion for fragment conservation as well as in determining the proper species to choose in vegetation recomposition projects.
\end{abstract}

Key words - forest conservation, forest fragments, Ribeirão Preto, soil-vegetation relationship

RESUMO - (Relação entre o solo e a composição florística de remanescentes de vegetação natural no Município de Ribeirão Preto, SP). Visando o estabelecimento da relação entre as características do solo e a composição florística, foi efetuado levantamento florístico em 95 fragmentos de vegetação natural em Ribeirão Preto. Foram registradas 509 espécies arbóreas pertencentes a 71 famílias botânicas. Uma análise de correspondência retificada (DCA) e uma análise de agrupamentos utilizando a distância relativa de Sørensen indicaram a existência de três grupos florísticos, associados aos tipos de solos. A aplicação de um procedimento de permutação (MRPP) indicou que os grupos são consistentes. Um grupo maior associado aos solos derivados do basalto, Latossolo Roxo e Litossolo, pôde ser subdividido em dois subgrupos de acordo com o grau de decomposição da rocha, identificados como mata mesófila e mata decídua, respectivamente. Outros dois grupos foram identificados, um associado ao Latossolo Vermelho Escuro e Vermelho Amarelo, cerradão, e outro ao solo Hidromórfico, mata paludícola. Cada grupo apresentou uma composição florística característica. Considerando as espécies arbóreas mais comuns, cerca de $65 \%$ tendem a ocorrer de forma diferenciada entre os tipos de solos. Elevada proporção das espécies ocorreu em pequeno número de fragmentos, e cada remanescente apresentou alguma espécie considerada regionalmente rara. A associação observada entre o solo e a composição florística dos remanescentes poderá contribuir para o estabelecimento de critérios para conservação dos fragmentos de vegetação, bem como na indicação das espécies apropriadas para plantio nos projetos de recomposição da vegetação em diferentes regiões da cidade.

Palavras-chave - conservação florestal, fragmentos florestais, relação solo vegetação, Ribeirão Preto

\section{Introdução}

A região do Estado de São Paulo onde se situa o Município de Ribeirão Preto foi bastante explorada para

1. Universidade de São Paulo, Faculdade de Filosofia, Ciências e Letras de Ribeirão Preto, Departamento de Biologia, Av. Bandeirantes 3900, 14040-901 Ribeirão Preto, SP, Brasil.

2. Universidade Estadual de Campinas, Instituto de Biologia, Departamento de Botânica, Caixa Postal 6109, 13083-970 Campinas, SP, Brasil.

3. Instituto Agronômico (IAC), Núcleo de Pesquisa e Desenvolvimento Jardim Botânico - CEC, Caixa Postal 28, 13001-970 Campinas, SP, Brasil.

4. Autor para correspondência: olgakot@usp.br o cultivo de café a partir de meados do século XIX e início do século XX (Victor 1975), e posteriormente para o cultivo de cana-de-açúcar (Kronka et al. 1998, Kotchetkoff-Henriques 2003). Atualmente a vegetação natural encontra-se muito reduzida e fragmentada.

Na região Tropical, associações entre as condições ambientais, a fisionomia e a composição florística dos remanescentes de vegetação nativa são conhecidas. Estudos realizados na África e na América Central mostraram que as características edáficas influenciam a distribuição das espécies arbóreas (Newbery \& Proctor 1984, Basnet 1992, Johnston 1992, Clark et al. 
1995, 1998, 1999, Swaine 1996, Clark 2002). A mesma relação foi observada em trabalhos que relacionam os tipos de solo com fisionomias de cerrado no Brasil Central (Felfili \& Silva Júnior 1993, Felfili et al. 1998, Ribeiro \& Walter 1998). No interior do Estado de São Paulo, Salis et al. (1995) e Torres et al. (1997) observaram que áreas em condições semelhantes de clima, altitude e tipo de solo apresentam maiores similaridades florísticas.

Entretanto, poucos trabalhos analisaram a ocorrência de variação florística associada a variações edáficas em escala espacial muito reduzida, e dentro da mesma região climática (Oliveira Filho et al. 1994a, b, Bertani et al. 2001, Costa \& Araújo 2001, Botrel et al. 2002, Soares et al. 2003). Variações deste tipo, dentro da mesma formação florestal, evidenciam a ocorrência diferencial de espécies em diferentes tipos de solo.

Apesar de escassos, os estudos realizados em escala espacial reduzida indicam que, dentro de uma mesma região climática, o tipo de solo pode ser utilizado como indicativo da composição florística a ser implantada em projetos de recomposição da vegetação (Rodrigues \& Gandolfi 1996).

Conhecer a vegetação natural e a sua relação com os solos onde ocorrem, além de poder auxiliar na conservação da biodiversidade local, pode contribuir para orientar os projetos de restauração da vegetação. Neste trabalho é estudada a relação entre os tipos de solo e a composição florística de remanescentes de vegetação no Município de Ribeirão Preto, buscando avaliar as fisionomias vegetais existentes e indicar quais as espécies indicadas para recuperação da vegetação natural, com base na ocorrência das espécies em tipos diferentes de solo.

\section{Material e métodos}

A área de estudo - O Município de Ribeirão Preto possui uma área de $651 \mathrm{~km}^{2}$ e situa-se a nordeste do Estado de São Paulo. Apresenta clima com sazonalidade marcada, com verão chuvoso e inverno seco. Dados coletados na Estação Experimental de Ribeirão Preto (IAC, $21^{\circ} 11^{\prime}$ S e $47^{\circ} 48^{\prime}$ W, $621 \mathrm{~m}$ de altitude) e no posto meteorológico situado no campus da Universidade de Ribeirão Preto (21 ${ }^{\circ} 11^{\prime} 60^{\prime}$ ' S e 47\%46'44' ' W, $590 \mathrm{~m}$ ), indicam temperatura média anual do ar de $22,6^{\circ} \mathrm{C}$ (período de 1981 a 2002), com médias mensais variando de $19,2^{\circ} \mathrm{C}$ em junho e julho a $24,4^{\circ} \mathrm{C}$ em fevereiro. A precipitação anual média é de $1.467,9 \mathrm{~mm}$ (período de 1937 a 2002), tendo sido registrada precipitação anual mínima de 735,4 mm (1944) e máxima de 2211,2 mm (1983). Os meses de outubro a março concentram $80 \%$ do total de chuvas, e, nos meses mais secos, junho a agosto, ocorrem apenas 5\% da precipitação (IPT 2000). De acordo com a classificação de Köppen, o município enquadra-se na categoria Aw (IPT 2000). O relevo é suave ondulado, com altitude variando entre $510 \mathrm{~m}$ na margem do rio Pardo e cerca de $800 \mathrm{~m}$ a oeste, na divisa com Cravinhos.

Em 1983 foi publicado o levantamento pedológico semidetalhado do Estado de São Paulo, quadrícula de Ribeirão Preto (Oliveira \& Prado 1983), mostrando que grande extensão do município é recoberta por Latossolo Roxo (cerca de 73\%), e em menor extensão por Latossolo Vermelho Escuro e Vermelho Amarelo (17\%). Em pequena extensão ocorrem Solos Litólicos (5\%) e Hidromorficos (4,5\%). De acordo com o atual Sistema Brasileiro de Classificação de Solos, o Latossolo Roxo corresponde ao Latossolo Vermelho Eutroférrico ou Distroférrico, o Latossolo Vermelho Escuro ao Latossolo Vermelho Eutrófico ou Distrófico, Latossolo Vermelho Amarelo, os solos Litólicos ao Neossolo Litólico e os solos hidromorficos aos Gleissolos (Oliveira 1999). Entretanto, como não foram efetuadas análises de solo dos fragmentos, neste trabalho é mantida a denominação utilizada pelo Mapa Pedológico Semidetalhado (Oliveira \& Prado 1983), indicando que os resultados obtidos estão baseados na informação contida naquele trabalho.

Sobre a base cartográfica elaborada pelo Instituto Florestal, que registra os remanescentes de vegetação natural a partir de imagens de satélite Landsat de 1997, foi delimitado o Município de Ribeirão Preto, sua área urbana e de expansão urbana, e as manchas de solo, de acordo com o Mapa Pedológico do Estado de São Paulo, quadrícula de Ribeirão Preto (Oliveira \& Prado 1983). Foram registrados 102 fragmentos de vegetação natural com área superior a 1,5 ha (figura 1).

Métodos - Foram avaliados 95 dos 102 fragmentos identificados no mapa de vegetação natural do município do Atlas do Programa Biota/Fapesp (http://sinbiota.cria.org.br/ atlas). Sete fragmentos não foram considerados na análise dos dados, sendo três não amostrados devido a dificuldades de acesso e quatro por apresentarem elevada proporção de espécies introduzidas. Os fragmentos foram georreferenciados com auxílio de um GPS Garmin $12 \mathrm{CX}$.

Em cada fragmento florestal amostrado foi efetuado levantamento florístico expedito (Ratter et al. 2001, modificado para ser aplicado por uma pessoa), sendo registrada a ocorrência das diferentes espécies arbóreas lenhosas em intervalos consecutivos de 15 minutos, até que em dois intervalos seguidos fossem acrescentadas duas ou menos espécies à listagem florística do local. O esforço de coleta nos intervalos foi padronizado, de forma a não incluir o tempo utilizado para abrir picadas ou coletar exemplares muito altos. Foram coletadas amostras de todos os indivíduos, que foram identificados por comparação com exemplares depositados nos herbários IAC, SPFR (USP - Ribeirão Preto), SP (IBt) e UEC (Unicamp), através de consulta a bibliografia especializada ou a especialistas. 
Foi utilizada uma análise de correspondência retificada (DCA, "detrended correspondence analysis"), processada pelo programa PC-ORD 4.0 (McCune \& Mefford 1999) para ordenar os fragmentos de vegetação de acordo com a similaridade florística entre eles. Esta análise foi baseada na matriz de ocorrência das espécies encontradas nos 95 fragmentos de vegetação estudados. Este tipo de análise indireta é indicada para evidenciar padrões de variação na composição de espécies relacionadas com características ambientais (ter Braak 1995). A classe de solo predominante no local de cada fragmento, de acordo com o mapa pedológico do Estado de São Paulo (Oliveira \& Prado 1983), foi incluída como variável categórica e relacionada com a presença das espécies arbóreas. A mesma matriz foi utilizada em análise de agrupamento utilizando a distância relativa de Sørensen e o método de ligação pela média do grupo - UPGMA, também processada pelo PC-ORD 4.0. A distância relativa de Sørensen foi adotada para corrigir distorções devido à variação na riqueza de espécies entre os fragmentos (McCune \& Mefford 1999). A delimitação dos grupos fisionômicos ocorreu baseada nos resultados destas análises.
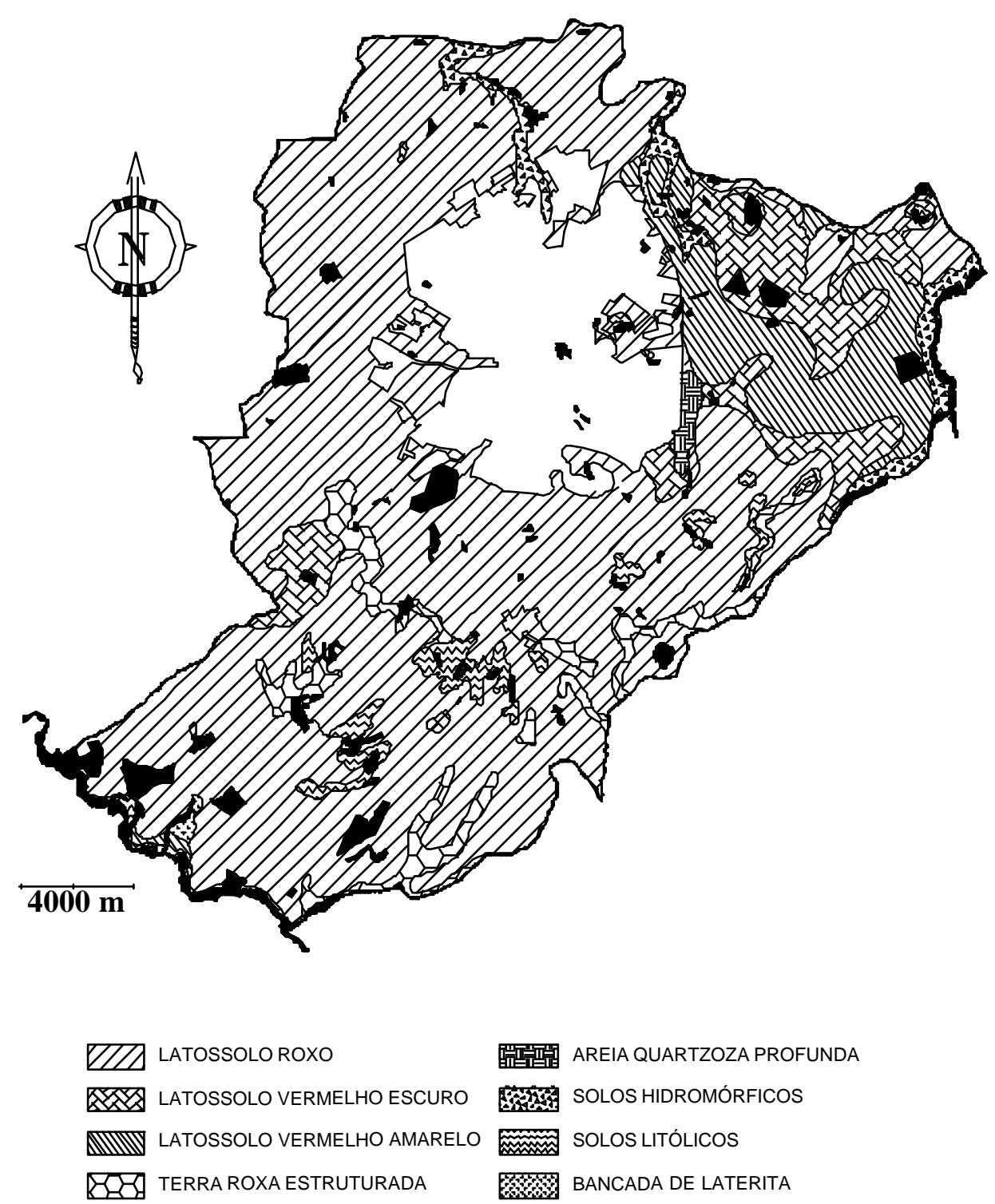

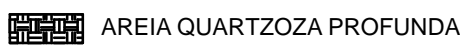

SOLOS HIDROMÓRFICOS

SOLOS LITÓLICOS

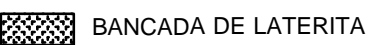

- Vegetação natural

Figura 1. Município de Ribeirão Preto, indicando os tipos de solo (Oliveira \& Prado 1983) e os remanescentes de vegetação natural (Instituto Florestal). A região em branco corresponde à área urbana do município (Prefeitura Municipal).

Figure 1. Ribeirão Preto municipality, with soils types (Oliveira \& Prado 1983) and remnants of the native vegetation (Forest Institut). The white region correspond to the urban area (City Hall). 
A associação entre os tipos de solo e a composição florística foi avaliada através de um procedimento de permutação, "multi-response permutation procedure" (MRPP). Neste procedimento foi também adotada a distância relativa de Sørensen (McCune \& Mefford 1999). Inicialmente, foram testados três grupos, reunindo os tipos de solos de acordo com os resultados obtidos na análise de correspondência. O mesmo procedimento foi executado utilizando todas as classes de solos indicadas.

A ocorrência de espécies com preferência por tipo de solo foi analisada através da aplicação do teste qui-quadrado (Sokal \& Rohlf 1995) para as espécies nativas que foram registradas em mais de 20 fragmentos. Para esta análise, foram considerados 19 fragmentos situados sobre Latossolo Vermelho Escuro e Latossolo Vermelho Amarelo, denominados Latossolo Vermelho, 45 fragmentos situados sobre Latossolo Roxo, 17 fragmentos situados sobre Litossolo e 11 situados sobre solo Hidromórfico. Não foram considerados três fragmentos que ocorreram em mais de um tipo de solo. A frequêencia esperada das espécies em cada tipo de solo foi obtida multiplicando o número de ocorrências da espécie pela razão entre o número de fragmentos em determinado tipo de solo e o número total de fragmentos.

\section{Resultados}

Os remanescentes de vegetação natural em Ribeirão Preto ocupam 2.535,67 ha, ou seja, 3,89\% da área do município. Os fragmentos de vegetação analisados apresentaram 509 espécies arbóreoarbustivas, distribuídas em 71 famílias botânicas, sendo 31 espécies exóticas (tabela 1).

Ocorreram três grupos florísticos, que podem ser associados aos tipos de solo (tabela 1, figura 2). Os fragmentos situados sobre Latossolo Roxo e Litossolo, reunidos à esquerda do eixo 1 (figura 2), estão separados daqueles situados sobre Latossolo Vermelho Escuro e Vermelho Amarelo, reunidos à direita do mesmo eixo. Os fragmentos situados sobre solo hidromórfico estão separados dos demais, na porção superior do gráfico.

A análise de agrupamento (figura 3) mostrou a mesma estrutura dos grupos. Houve a separação de um grupo de cerrados de um grupo de matas, incluindo os mesmos fragmentos que ocupam os extremos do gradiente obtido no eixo 1 da DCA. O grupo formado pelas matas em solos hidromórficos foram separados das demais matas, incluindo também os mesmos fragmentos destacados na porção superior do eixo 2 da DCA. O grupo de matas apresentou-se subdividido, reunindo em um ramo as matas sobre Latossolo e as matas sobre Litossolo em outro.
Houve diferença significativa na composição florística das matas entre os três de solo grupos (MRPP, $\mathrm{p}<0,001$ ), sendo que a variação dentro dos grupos foi pequena (distâncias médias: $\mathrm{LR}+\mathrm{Li}=0,34, \mathrm{Hi}=0,40$, $\mathrm{LA}+\mathrm{LV}=0,27)$ e a homogeneidade dentro do grupo foi elevada $(A=0,33)$. A repetição deste procedimento utilizando as 5 classes de solo registrou resultados também significativos $(\mathrm{p}<0,001)$, sendo a distância média dentro dos grupos também pequenas ( $\mathrm{LR}=0,36$, $\mathrm{Hi}=0,40, \mathrm{Li}=0,15, \mathrm{LA}=0,08, \mathrm{LE}=0,39)$, e a homogeneidade dentro dos grupos também elevada $(\mathrm{A}=0,37)$. Estes resultados indicam que o tipo de solo exerce influência na composição florística dos fragmentos.

Composição florística - Cada grupo apresentou características florísticas distintas. O primeiro e maior grupo incluiu todos os fragmentos situados sobre Latossolo Roxo, Terra Roxa Estruturada e Solos Litólicos. Este grupo foi formado por 64 fragmentos, que reuniram 416 espécies arbustivo-arbóreas, das quais 25 foram espécies exóticas. Apenas cinco espécies (Rhamnidium elaeocarpum, Pterogyne nitens, Celtis iguanea, Machaerium stipitatum e Acacia polyphylla) ocorreram em mais de $75 \%$ dos fragmentos, e 39,2\% ocorreram apenas em um ou dois fragmentos.

É possível reconhecer uma subdivisão neste grupo, que reuniu de um lado os fragmentos que ocorreram sobre Latossolo, e de outro aqueles que ocorreram sobre Litossolo. Nestas situações, os fragmentos apresentaram fisionomias distintas. A similaridade florística destes dois grupos foi elevada, mas um deles apresentou um subconjunto menor de espécies. Das espécies registradas neste grupo, 37,7\% não ocorreram sobre Litossolo, e apenas $11,5 \%$ não ocorreram sobre Latossolo Roxo.

O subgrupo que ocorreu sobre Latossolo foi formado por matas que permanecem verdes durante todo o ano, apesar de ocorrer perda acentuada de folhas na época seca. Estes fragmentos, associados aos solos mais profundos, constituíram o subgrupo de matas mesófilas semidecíduas (M), e foi formado por 29 fragmentos, onde foram registradas 368 espécies arbóreo-arbustivas, sendo 17 espécies exóticas. A maioria das espécies ocorreu em poucos fragmentos, sendo que $28,8 \%$ apresentaram ocorrência única e $14,1 \%$ ocorreram em dois fragmentos, totalizando $42,9 \%$ das espécies com ocorrência restrita. Apenas 2,2\% ocorreram em mais de $75 \%$ dos fragmentos.

Outro subgrupo incluiu os fragmentos situados em solo Litólico ou em Latossolo Roxo com pedregosidade acentuada, e que apresentaram fisionomia distinta, 
Tabela 1. Espécies arbóreas registradas em 95 fragmentos de vegetação natural em Ribeirão Preto, SP, indicando o número de ocorrências nas formações vegetais presentes. $\mathrm{P}=$ mata paludícola, $\mathrm{C}=$ cerradão, $\mathrm{M}=$ mata mesófila, $\mathrm{D}=$ mata decídua, $\chi^{2}=$ resultado do teste qui-quadrado, indicando se a espécie foi indiferente (NS) ou apresentou preferência por Latossolo Roxo (LR), Latossolo Vermelho (LV), Litossolo (Li) ou solo Hidromórfico (Hi).

Table 1. Tree species registered in 95 natural vegetation fragments of Ribeirão Preto, SP, indicanting the number of ocurrences in the existing vegetation formation. $\mathrm{P}=$ swamp forest, $\mathrm{C}=$ "cerradão", $\mathrm{M}=$ mesophilous forest, $\mathrm{D}=$ decidous forest, $\chi^{2}=$ chisquare test, indicating the species preferences for Purple Latossol (LR), Red Latossol (LV), Lithosol (Li) or Hidromorfic Soil (Hi).

\begin{tabular}{|c|c|c|c|c|c|}
\hline \multirow[b]{2}{*}{ Família/Espécie } & \multicolumn{4}{|c|}{ Grupo } & \multirow[t]{2}{*}{$\chi^{2}$} \\
\hline & $\mathrm{P}$ & $\mathrm{C}$ & M & $\mathrm{D}$ & \\
\hline \multicolumn{6}{|l|}{ ANACARDIACEAE } \\
\hline Astronium fraxinifolium Schott ex Spreng. & 0 & 7 & 7 & 0 & \\
\hline Astronium graveolens Jacq. & 1 & 7 & 19 & 5 & NS \\
\hline Lithraea molleoides (Vell.) Engl. & 0 & 0 & 4 & 5 & \\
\hline Mangifera indica $\mathrm{L}$. & 0 & 0 & 1 & 7 & \\
\hline Myracrodruon urundeuva Allemão & 0 & 3 & 11 & 29 & $\mathrm{Li}$ \\
\hline Schinus terebinthifolius Raddi & 2 & 0 & 1 & 0 & \\
\hline Spondias mombin L. & 0 & 0 & 2 & 0 & \\
\hline Tapirira guianensis Aubl. & 9 & 13 & 7 & 1 & LV \\
\hline Tapirira obtusa (Benth.) D.J. Mitch. & 0 & 1 & 2 & 0 & \\
\hline \multicolumn{6}{|l|}{ ANNONACEAE } \\
\hline Annona cacans Warm. & 0 & 1 & 10 & 0 & \\
\hline Annona coriacea Mart. & 0 & 12 & 2 & 0 & \\
\hline Annona crassiflora Mart. & 0 & 3 & 0 & 0 & \\
\hline Annona dioica A.St.-Hil. & 0 & 1 & 0 & 1 & \\
\hline Annona montana Macfad. & 0 & 0 & 0 & 1 & \\
\hline Duguetia furfuracea (A.St.-Hil.) Benth. \& Hook.f. & 0 & 4 & 0 & 0 & \\
\hline Duguetia lanceolata A.St.-Hil. & 1 & 6 & 14 & 1 & LV \\
\hline Ephedranthus parviflorus S.Moore & 0 & 1 & 1 & 0 & \\
\hline Guatteria nigrescens Mart. & 0 & 2 & 0 & 0 & \\
\hline Rollinia emarginata Schltdl. & 0 & 0 & 1 & 0 & \\
\hline Rollinia mисоsa (Jacq.) Baill. & 0 & 0 & 6 & 3 & \\
\hline Rollinia sericea (R.E.Fr.) R.E.Fr. & 0 & 0 & 0 & 1 & \\
\hline Rollinia sylvatica (A.St.-Hil.) Mart. & 0 & 0 & 10 & 4 & \\
\hline Unonopsis lindmanii R.E.Fr. & 2 & 2 & 7 & 1 & \\
\hline Xylopia aromática (Lam.) Mart. & 4 & 16 & 8 & 4 & LV \\
\hline Xylopia brasiliensis Spreng. & 3 & 0 & 3 & 0 & \\
\hline \multicolumn{6}{|l|}{ APOCYNACEAE } \\
\hline Aspidosperma cylindrocarpon Müll.Arg. & 0 & 0 & 14 & 5 & \\
\hline Aspidosperma parvifolium A.DC. & 0 & 0 & 6 & 9 & \\
\hline Aspidosperma polyneuron Müll.Arg. & 0 & 0 & 8 & 0 & \\
\hline Aspidosperma ramiflorum Müll.Arg. & 0 & 0 & 1 & 0 & \\
\hline Aspidosperma spruceanum Benth. ex Müll.Arg. & 0 & 0 & 1 & 0 & \\
\hline Aspidosperma subincanum Mart. & 0 & 0 & 2 & 0 & \\
\hline Aspidosperma tomentosum Mart. & 0 & 3 & 0 & 0 & \\
\hline Himatanthus obovatus (Müll.Arg.) Woodson & 0 & 1 & 0 & 0 & \\
\hline Tabernaemontana hystrix Steud. & 0 & 0 & 0 & 1 & \\
\hline Thevetia peruviana (Pers.) K.Schum. & 0 & 0 & 1 & 0 & \\
\hline \multicolumn{6}{|l|}{ AQUIFOLIACEAE } \\
\hline Ilex cerasifolia Reissek & 0 & 4 & 1 & 0 & \\
\hline \multicolumn{6}{|l|}{ ARALIACEAE } \\
\hline Aralia warmingiana (Marchal) J.Wen & 0 & 0 & 6 & 8 & \\
\hline
\end{tabular}


continuação

\begin{tabular}{|c|c|c|c|c|c|}
\hline \multirow[b]{2}{*}{ Família/Espécie } & \multicolumn{4}{|c|}{ Grupo } & \multirow[t]{2}{*}{$\chi^{2}$} \\
\hline & $\mathrm{P}$ & $\mathrm{C}$ & M & $\mathrm{D}$ & \\
\hline Dendropanax cuneatus (DC.) Decne. \& Planch. & 5 & 0 & 4 & 0 & \\
\hline Didymopanax calvus (Cham.) Decne. \& Planch. & 1 & 1 & 5 & 1 & \\
\hline Didymopanax vinosus (Cham. \& Schltdl.) Marchal & 0 & 12 & 0 & 0 & \\
\hline Didymopanax morototoni (Aubl.) Decne. \& Planch. & 3 & 4 & 18 & 11 & NS \\
\hline \multicolumn{6}{|l|}{ ARECACEAE } \\
\hline Acrocomia aculeata (Jacq.) Lodd. ex Mart. & 3 & 0 & 8 & 10 & \\
\hline Dypsis lutescens (H.Wendl.) Beentje \& J.Dransf. & 1 & 0 & 0 & 0 & \\
\hline Euterpe edulis Mart. & 1 & 0 & 1 & 2 & \\
\hline Geonoma brevispatha Barb.Rodr. & 5 & 0 & 1 & 0 & \\
\hline Syagrus flexuosa (Mart.) Becc. & 0 & 4 & 0 & 0 & \\
\hline Syagrus oleracea (Mart.) Becc. & 0 & 1 & 2 & 0 & \\
\hline Syagrus romanzoffiana (Cham.) Glassman & 0 & 2 & 4 & 1 & \\
\hline \multicolumn{6}{|l|}{ ASTERACEAE } \\
\hline Baccharis dracunculifolia DC. & 0 & 0 & 1 & 5 & \\
\hline Chresta sphaerocephala DC. & 0 & 1 & 0 & 1 & \\
\hline Chromolaena laevigatum (Lam.) R.M.King \& H.Rob. & 0 & 0 & 1 & 1 & \\
\hline Gochnatia barrosii Cabrera & 0 & 1 & 2 & 2 & \\
\hline Gochnatia discolor Baker & 0 & 1 & 0 & 0 & \\
\hline Gochnatia polymorpha (Less.) Cabrera & 0 & 5 & 0 & 0 & \\
\hline Pingraea oxydonta (DC.) F.Hellw. & 0 & 0 & 0 & 1 & \\
\hline Vernonanthura ferruginea Less. & 0 & 0 & 2 & 3 & \\
\hline Vernonanthura phosphorica Less. & 2 & 0 & 1 & 7 & \\
\hline Vernonia rubriramia Mart. & 0 & 6 & 0 & 0 & \\
\hline \multicolumn{6}{|l|}{ BIGNONIACEAE } \\
\hline Arrabidaea brachypoda (DC.) Bureau & 0 & 2 & 0 & 0 & \\
\hline Cybistax antisyphilitica (Mart.) Mart. & 0 & 2 & 1 & 1 & \\
\hline Jacaranda cuspidifolia Mart. ex A.DC. & 0 & 1 & 2 & 3 & \\
\hline Jacaranda puberula Cham. & 0 & 10 & 0 & 0 & \\
\hline Tabebuia chrysotricha (Mart. ex DC.) Standl. & 0 & 1 & 0 & 1 & \\
\hline Tabebuia heptaphylla (Vell.) Toledo & 0 & 0 & 9 & 8 & \\
\hline Tabebuia insignis (Miq.) Sandwith & 3 & 0 & 0 & 1 & \\
\hline Tabebuia ochracea (Cham.) Standl. & 2 & 9 & 4 & 8 & NS \\
\hline Tabebuia roseo-alba (Ridl.) Sandwith & 0 & 0 & 0 & 2 & \\
\hline Tabebuia serratifolia (Vahl) G.Nicholson & 0 & 3 & 11 & 5 & \\
\hline Tabebuia umbellata (Sond.) Sandwith & 0 & 0 & 0 & 1 & \\
\hline Tabebuia vellosoi Toledo & 2 & 0 & 5 & 4 & \\
\hline Tecoma stans $(\mathrm{L}$.$) Juss. ex Kunth$ & 0 & 0 & 1 & 8 & \\
\hline Zeyheria tuberculosa (Vell.) Bureau & 0 & 0 & 13 & 0 & \\
\hline \multicolumn{6}{|l|}{ BOMBACACEAE } \\
\hline Ceiba speciosa (A.St.-Hil.) Ravenna & 0 & 0 & 17 & 23 & LR \\
\hline Eriotheca candolleana (K.Schum.) A.Robyns & 0 & 0 & 1 & 0 & \\
\hline Eriotheca gracilipes (K. Schum.) A.Robyns & 0 & 3 & 0 & 0 & \\
\hline Pseudobombax grandiflorum (Cav.) A.Robyns & 0 & 0 & 4 & 0 & \\
\hline Pseudobombax longiflorum (Mart. \& Zucc.) A.Robyns & 0 & 2 & 0 & 0 & \\
\hline \multicolumn{6}{|l|}{ BORAGINACEAE } \\
\hline Cordia ecalyculata Vell. & 0 & 0 & 6 & 3 & \\
\hline Cordia guazumaefolia (Desv.) Roem. \& Schult. & 1 & 0 & 0 & 0 & \\
\hline Cordia myxa $\mathrm{L}$ & 0 & 0 & 0 & 1 & \\
\hline Cordia monosperma (Jacq.) Roem. \& Schult. & 0 & 0 & 0 & 1 & \\
\hline Cordia sellowiana Cham. & 0 & 2 & 6 & 1 & \\
\hline
\end{tabular}




\begin{tabular}{|c|c|c|c|c|c|}
\hline \multirow[b]{2}{*}{ Família/Espécie } & \multicolumn{4}{|c|}{ Grupo } & \multirow[t]{2}{*}{$\chi^{2}$} \\
\hline & $\mathrm{P}$ & $\mathrm{C}$ & $\mathrm{M}$ & $\mathrm{D}$ & \\
\hline Cordia superba Cham. & 0 & 0 & 3 & 1 & \\
\hline Cordia trichotoma (Vell.) Arráb. ex Steud. & 1 & 1 & 2 & 14 & \\
\hline \multicolumn{6}{|l|}{ BURSERACEAE } \\
\hline Protium heptaphyllum (Aubl.) Marchand & 1 & 6 & 10 & 0 & \\
\hline Protium ovatum Engl. & 0 & 3 & 0 & 0 & \\
\hline Protium spruceanum (Benth.) Engl. & 4 & 0 & 4 & 0 & \\
\hline Protium widgrenii Engl. & 1 & 1 & 5 & 0 & \\
\hline \multicolumn{6}{|l|}{ CARICACEAE } \\
\hline Jacaratia spinosa (Aubl.) A.DC. & 0 & 0 & 4 & 0 & \\
\hline \multicolumn{6}{|l|}{ CARYOCARACEAE } \\
\hline Caryocar brasiliense Cambess. & 0 & 8 & 0 & 0 & \\
\hline \multicolumn{6}{|l|}{ CECROPIACEAE } \\
\hline Cecropia glaziovii Snethlage & 0 & 0 & 1 & 2 & \\
\hline Cecropia pachystachya Trécul & 10 & 11 & 18 & 12 & $\mathrm{Hi}$ \\
\hline \multicolumn{6}{|l|}{ CELASTRACEAE } \\
\hline Cleiloclinium cognatus (Miers) A.C.Sm. & 0 & 1 & 1 & 0 & \\
\hline Maytenus floribunda Reissek & 0 & 0 & 6 & 10 & \\
\hline Maytenus robusta Reissek & 0 & 0 & 7 & 0 & \\
\hline Plenckia populnea Reissek & 0 & 1 & 0 & 0 & \\
\hline \multicolumn{6}{|l|}{ CHLORANTHACEAE } \\
\hline Hedyosmum brasiliense Miq. & 4 & 0 & 0 & 0 & \\
\hline CHRYSOBALANACEAE & $\chi$ & & & & \\
\hline Couepia grandiflora (Mart. \& Zucc.) Benth. ex Hook.f. & 0 & 8 & 1 & 0 & \\
\hline Hirtella gracilipes (Hook.f.) Prance & 2 & 2 & 2 & 0 & \\
\hline Licania humilis Cham. \& Schltdl. & 0 & 2 & 0 & 0 & \\
\hline \multicolumn{6}{|l|}{ CLUSIACEAE } \\
\hline Calophyllum brasiliense Cambess. & 8 & 0 & 5 & 0 & \\
\hline Clusia criuva Cambess. subsp. criuva & 1 & 0 & 0 & 0 & \\
\hline Garcinia gardneriana (Planch. \& Triana) Zappi & 1 & 0 & 2 & 0 & \\
\hline Kielmeyera coriacea Mart. \& Zucc. & 0 & 2 & 0 & 0 & \\
\hline \multicolumn{6}{|l|}{ COMBRETACEAE } \\
\hline Terminalia glabrescens Mart. & 1 & 10 & 14 & 2 & LV \\
\hline Terminalia modesta Eichler & 0 & 2 & 13 & 5 & \\
\hline Terminalia triflora (Griseb.) Lillo & 0 & 0 & 1 & 2 & \\
\hline \multicolumn{6}{|l|}{ CONNARACEAE } \\
\hline Connarus suberosus Planch. & 0 & 3 & 1 & 0 & \\
\hline \multicolumn{6}{|l|}{ CUNONIACEAE } \\
\hline Lamanonia ternata Vell. & 0 & 1 & 0 & 0 & \\
\hline \multicolumn{6}{|l|}{ EBENACEAE } \\
\hline Diospyros hispida A.DC. & 0 & 2 & 0 & 0 & \\
\hline Diospyros inconstans Jacq. & 0 & 0 & 2 & 4 & \\
\hline \multicolumn{6}{|l|}{ ELAEOCARPACEAE } \\
\hline Sloanea monosperma Vell. & 0 & 0 & 1 & 0 & \\
\hline \multicolumn{6}{|l|}{ ERYTROXYLACEAE } \\
\hline Erytroxylum anguifugum Mart. & 7 & 0 & 1 & 0 & \\
\hline Erytroxylum cuneifolium (Mart.) O.E.Schulz & 1 & 0 & 1 & 1 & \\
\hline Erytroxylum daphnites Mart. & 0 & 3 & 2 & 1 & \\
\hline Erytroxylum deciduum A.St.-Hil. & 0 & 4 & 0 & 0 & \\
\hline Erytroxylum nanum A.St.-Hil. & 0 & 0 & 1 & 1 & \\
\hline Erytroxylum pelleterianum A.St.-Hil. & 0 & 13 & 11 & 5 & $\begin{array}{l}\text { LV } \\
\text { continuc }\end{array}$ \\
\hline
\end{tabular}


continuação

\begin{tabular}{|c|c|c|c|c|c|}
\hline \multirow[b]{2}{*}{ Família/Espécie } & \multicolumn{4}{|c|}{ Grupo } & \multirow[t]{2}{*}{$\chi^{2}$} \\
\hline & $\mathrm{P}$ & $\mathrm{C}$ & M & $\mathrm{D}$ & \\
\hline Erytroxylum suberosum A.St.-Hil. & 0 & 2 & 0 & 0 & \\
\hline Erytroxylum subracemosum Turcz. & 0 & 0 & 0 & 1 & \\
\hline \multicolumn{6}{|l|}{ EUPHORBIACEAE } \\
\hline Acalypha cf. villosa Jacq. & 0 & 0 & 1 & 0 & \\
\hline Acalypha subvillosa Müll.Arg. & 0 & 0 & 1 & 0 & \\
\hline Actinostemon concepcionis (Chodat \& Hassl.) Hochr. & 1 & 10 & 20 & 5 & \\
\hline Alchornea glandulosa Poepp. & 3 & 0 & 10 & 5 & \\
\hline Croton floribundus Spreng. & 0 & 2 & 23 & 5 & LR \\
\hline Croton gracilipes Baill. & 0 & 0 & 2 & 6 & \\
\hline Croton piptocalyx Müll.Arg. & 0 & 0 & 10 & 1 & \\
\hline Croton salutaris Casar. & 0 & 0 & 1 & 0 & \\
\hline Croton urucurana Baill. & 10 & 1 & 9 & 5 & $\mathrm{Hi}$ \\
\hline Croton warmingii Müll.Arg. & 0 & 0 & 6 & 1 & \\
\hline Joannesia princeps Vell. & 1 & 0 & 0 & 1 & \\
\hline Mabea fistulifera Mart. & 0 & 4 & 4 & 0 & \\
\hline Manihot anomala Pohl & 0 & 0 & 0 & 1 & \\
\hline Manihot caerulescens (Spreng.) Müll.Arg. & 0 & 2 & 0 & 0 & \\
\hline Manihot esculenta Crantz & 0 & 0 & 0 & 1 & \\
\hline Manihot pilosa Pohl & 0 & 0 & 5 & 3 & \\
\hline Micrandra elata Müll.Arg. & 0 & 0 & 1 & 0 & \\
\hline Pera obovata (Klotzsch) Baill. & 0 & 3 & 0 & 0 & \\
\hline Phyllanthus acuminatus Vahl & 0 & 0 & 1 & 2 & \\
\hline Sapium glandulatum (Klotzsch) Baill. & 4 & 0 & 5 & 3 & \\
\hline Savia dictyocarpa Müll.Arg. & 0 & 10 & 0 & 0 & \\
\hline Sebastiania brasiliensis Spreng. & 4 & 0 & 3 & 1 & \\
\hline Sebastiania commersoniana Spreng. & 4 & 0 & 8 & 0 & \\
\hline \multicolumn{6}{|l|}{ FABACEAE } \\
\hline Acacia adhaerens Benth. & 0 & 0 & 0 & 1 & \\
\hline Acacia paniculata Willd. & 2 & 1 & 16 & 14 & NS \\
\hline Acacia plumosa Lowe & 1 & 0 & 4 & 1 & \\
\hline Acacia polyphylla DC. & 5 & 7 & 29 & 28 & NS \\
\hline Acosmium dasycarpum (Vogel) Yakovlev & 0 & 3 & 0 & 0 & \\
\hline Acosmium subelegans (Mohlenbr.) Yakovlev & 0 & 4 & 0 & 0 & \\
\hline Albizia adianthifolia (Schumach.) W.Wight & 0 & 0 & 16 & 10 & NS \\
\hline Albizia lebeck (L.) Benth. & 0 & 0 & 1 & 0 & \\
\hline Albizia niopodes (Spruce ex Benth.) Burkart & 1 & 0 & 11 & 21 & $\mathrm{LR}, \mathrm{Li}$ \\
\hline Albizia procera (Roxb.) Benth. & 0 & 0 & 1 & 2 & \\
\hline Anadenanthera macrocarpa (Benth.) Brenan & 1 & 1 & 12 & 19 & $\mathrm{Li}$ \\
\hline Anadenanthera peregrina (L.) Speg. & 3 & 15 & 3 & 1 & LV \\
\hline Andira anthelmia (Vell.) J.F.Macbr. & 3 & 6 & 8 & 2 & \\
\hline Andira vermifuga Mart. ex Benth. & 1 & 1 & 3 & 0 & \\
\hline Apuleia leiocarpa (Vogel) J.F.Macbr. & 0 & 0 & 1 & 2 & \\
\hline Bauhinia brevipes Vogel & 1 & 0 & 3 & 3 & \\
\hline Bauhinia holophylla (Bong.) Steud. & 0 & 6 & 1 & 0 & \\
\hline Bauhinia longifolia D.Dietr. & 0 & 0 & 7 & 4 & \\
\hline Bauhinia pentandra (Bong.) Vogel ex Steud. & 0 & 0 & 0 & 3 & \\
\hline Bauhinia radiata Vell. & 0 & 2 & 1 & 1 & \\
\hline Bauhinia rufa (Bong.) Steud. & 0 & 3 & 0 & 0 & \\
\hline Bauhinia ungulata $\mathrm{L}$. & 1 & 0 & 8 & 6 & \\
\hline Bowdichia virgilioides Kunth & 0 & 7 & 0 & 0 & \\
\hline
\end{tabular}




\begin{tabular}{|c|c|c|c|c|c|}
\hline \multirow[b]{2}{*}{ Família/Espécie } & \multicolumn{4}{|c|}{ Grupo } & \multirow[t]{2}{*}{$\chi^{2}$} \\
\hline & $\mathrm{P}$ & $\mathrm{C}$ & M & $\mathrm{D}$ & \\
\hline Caesalpinia ferrea Mart. & 0 & 0 & 1 & 0 & \\
\hline Caesalpinia pluviosa var. peltophoroides (Benth.) G.P.Lewis & 0 & 0 & 0 & 1 & \\
\hline Calliandra tweediei Benth. & 0 & 0 & 0 & 1 & \\
\hline Cassia ferruginea (Schrader) Schrader ex DC. & 0 & 0 & 2 & 0 & \\
\hline Centrolobium tomentosum Guillemin ex Benth. & 0 & 0 & 0 & 3 & \\
\hline Copaifera langsdorffii Desf. & 4 & 16 & 20 & 5 & LV \\
\hline Dalbergia frutescens (Vell.) Britton & 0 & 0 & 8 & 0 & \\
\hline Dalbergia miscolobium Kunth & 0 & 6 & 0 & 0 & \\
\hline Dimorphandra mollis Benth. & 0 & 10 & 2 & 0 & \\
\hline Diptychandra aurantiaca Tul. & 0 & 6 & 0 & 0 & \\
\hline Enterolobium contortisiliquum (Vell.) Morong & 1 & 0 & 12 & 11 & NS \\
\hline Enterolobium gummiferum (Mart.) J.F.Macbr. & 0 & 3 & 0 & 0 & \\
\hline Erythrina speciosa Andrews & 0 & 0 & 0 & 1 & \\
\hline Gliricidia sepium (Jacq.) Kunth ex Walp. & 0 & 0 & 1 & 3 & \\
\hline Holocalyx balansae Micheli & 0 & 0 & 14 & 9 & LR \\
\hline Hymenaea courbaril $\mathrm{L}$ & 0 & 1 & 16 & 6 & LR \\
\hline Hymenaea stigonocarpa Mart. ex Hayne & 1 & 2 & 1 & 0 & \\
\hline Indigofera suffruticosa Mill. & 0 & 0 & 0 & 2 & \\
\hline Inga ingoides (Rich.) Willd. & 0 & 0 & 5 & 3 & \\
\hline Inga marginata Willd. & 2 & 0 & 14 & 6 & LR \\
\hline Inga subnuda Salzm. ex Benth. & 0 & 2 & 7 & 2 & \\
\hline Inga vera subsp. affinis DC. & 8 & 0 & 8 & 3 & \\
\hline Leucaena glauca Benth. & 0 & 0 & 0 & 1 & \\
\hline Leucaena leucocephala (Lam.) de Wit & 0 & 0 & 1 & 0 & \\
\hline Lonchocarpus campestris Mart. ex Benth. & 0 & 0 & 0 & 1 & \\
\hline Lonchocarpus cultratus (Vell. ) A.M.G. Azevedo \& H.C.Lima & 2 & 0 & 11 & 9 & NS \\
\hline Lonchocarpus muehlbergianus Hassl. & 0 & 0 & 0 & 3 & \\
\hline Machaerium acutifolium Vogel & 2 & 14 & 6 & 3 & $\mathrm{LV}$ \\
\hline Machaerium brasiliense Vogel & 0 & 0 & 1 & 0 & \\
\hline Machaerium hirtum (Vell.) Stellfeld & 6 & 2 & 20 & 24 & NS \\
\hline Machaerium nyctitans (Vell.) Benth. & 0 & 0 & 7 & 2 & \\
\hline Machaerium stipitatum(DC.) Vogel & 2 & 1 & 23 & 30 & $\mathrm{LR}, \mathrm{Li}$ \\
\hline Machaerium vestitum Vogel & 0 & 2 & 11 & 8 & NS \\
\hline Machaerium villosum Vogel & 1 & 2 & 16 & 3 & NS \\
\hline Mimosa acerba Benth. & 0 & 0 & 1 & 0 & \\
\hline Mimosa asperata $\mathrm{L}$. & 0 & 0 & 0 & 1 & \\
\hline Mimosa bimucronata (DC.) Kuntze & 3 & 0 & 0 & 1 & \\
\hline Myroxylon peruiferum L.f. & 0 & 1 & 15 & 9 & LR \\
\hline Ormosia arborea (Vell.) Harms & 2 & 2 & 8 & 0 & \\
\hline Peltophorum dubium (Spreng.) Taub. & 2 & 0 & 11 & 12 & NS \\
\hline Piptadenia gonoacantha (Mart.) J.F.Macbr. & 1 & 0 & 5 & 3 & \\
\hline Plathymenia reticulata Benth. & 0 & 10 & 0 & 1 & \\
\hline Platycyamus regnelli Benth. & 0 & 0 & 16 & 7 & NS \\
\hline Platypodium elegans Vogel & 4 & 7 & 15 & 14 & NS \\
\hline Pterocarpus rohrii Vahl & 0 & 1 & 6 & 0 & \\
\hline Pterodon emarginatus Vogel & 0 & 14 & 2 & 1 & \\
\hline Pterogyne nitens Tul. & 1 & 2 & 19 & 31 & $\mathrm{LR}, \mathrm{Li}$ \\
\hline Schizolobium parahyba (Vell.) S.F.Blake & 0 & 0 & 3 & 5 & \\
\hline Senna cernua (Balb.) H.S.Irwin \& Barneby & 0 & 0 & 0 & 1 & \\
\hline Senna hirsuta (L.) H.S.Irwin \& Barneby & 0 & 0 & 0 & 3 & \\
\hline
\end{tabular}


continuação

\begin{tabular}{|c|c|c|c|c|c|}
\hline \multirow[b]{2}{*}{ Família/Espécie } & \multicolumn{4}{|c|}{ Grupo } & \multirow[t]{2}{*}{$\chi^{2}$} \\
\hline & $\mathrm{P}$ & $\mathrm{C}$ & M & $\mathrm{D}$ & \\
\hline Senna macranthera (DC. ex Collad.) H.S.Irwin \& Barneby & 0 & 0 & 4 & 4 & \\
\hline Senna multijuga (Rich.) H.S.Irwin \& Barneby & 0 & 0 & 1 & 0 & \\
\hline Senna occidentalis (L.) Link & 0 & 0 & 0 & 1 & \\
\hline Senna pendula (Humb. \& Bonpl. ex Willd.) H.S.Irwin \& Barneby & 1 & 0 & 1 & 3 & \\
\hline Senna racemosa (Mill.) H.S.Irwin \& Barneby & 0 & 0 & 1 & 0 & \\
\hline Senna rugosa (G. Don) H.S.Irwin \& Barneby & 0 & 1 & 0 & 0 & \\
\hline Senna siamea (Lam.) H.S.Irwin \& Barneby & 0 & 0 & 1 & 1 & \\
\hline Senna spectabilis (DC.) H.S.Irwin \& Barneby & 0 & 0 & 1 & 2 & \\
\hline Stryphnodendron obovatum Benth. & 0 & 11 & 3 & 1 & \\
\hline Sweetia fruticosa Spreng. & 0 & 1 & 15 & 7 & NS \\
\hline Tipuana tipu (Benth.) Kuntze & 0 & 0 & 0 & 1 & \\
\hline Vatairea macrocarpa (Benth.) Ducke & 0 & 7 & 1 & 0 & \\
\hline \multicolumn{6}{|l|}{ FLACOURTIACEAE } \\
\hline Casearia gossypiosperma Briq. & 0 & 2 & 21 & 15 & NS \\
\hline Casearia grandiflora Cambess. & 0 & 15 & 4 & 0 & \\
\hline Casearia rupestris Eichler & 0 & 0 & 1 & 6 & \\
\hline Casearia sylvestris $\mathrm{Sw}$. & 2 & 5 & 16 & 14 & NS \\
\hline Prockia crucis P.Browne ex L. & 0 & 0 & 15 & 18 & LR \\
\hline Xylosma pseudosalzmanii Sleumer & 0 & 0 & 2 & 2 & \\
\hline \multicolumn{6}{|l|}{ ICACINACEAE } \\
\hline Citronella gongonha (Mart.) R.A.Howard & 3 & 0 & 0 & 0 & \\
\hline Citronella paniculata (Mart.) R.A.Howard & 0 & 0 & 1 & 0 & \\
\hline \multicolumn{6}{|l|}{ LACISTEMATACEAE } \\
\hline Lacistema hasslerianum Chodat & 5 & 1 & 6 & 1 & \\
\hline \multicolumn{6}{|l|}{ LAURACEAE } \\
\hline Aniba heringerii Vattimo & 2 & 0 & 0 & 0 & \\
\hline Cryptocarya aschersoniana $\mathrm{Mez}$ & 1 & 1 & 4 & 0 & \\
\hline Endlicheria paniculata (Spreng.) J.F.Macbr. & 0 & 0 & 2 & 1 & \\
\hline Nectandra cuspidata Nees \& Mart. & 0 & 4 & 4 & 0 & \\
\hline Nectandra grandiflora Nees \& Mart. ex Nees & 2 & 0 & 0 & 0 & \\
\hline Nectandra megapotamica (Spreng.) Mez & 7 & 0 & 15 & 17 & LR \\
\hline Nectandra nitidula Nees \& Mart. & 2 & 0 & 0 & 0 & \\
\hline Ocotea sp. 1 & 0 & 10 & 4 & 0 & \\
\hline Ocotea beulahiae Baitello & 0 & 0 & 1 & 0 & \\
\hline Ocotea cf. lanata (Nees \& Mart.) Mez & 1 & 0 & 0 & 1 & \\
\hline Ocotea corymbosa (Meisn.) Mez & 0 & 9 & 3 & 0 & \\
\hline Ocotea indecora (Schott) Mez & 0 & 0 & 4 & 0 & \\
\hline Ocotea lancifolia (Schott) $\mathrm{Mez}$ & 1 & 0 & 0 & 0 & \\
\hline Ocotea minarum (Nees \& Mart.) Mez & 0 & 1 & 2 & 1 & \\
\hline Ocotea pulchella Mart. & 0 & 2 & 1 & 1 & \\
\hline Ocotea sp. 2 & 0 & 2 & 0 & 0 & \\
\hline Ocotea velloziana (Meisn.) Mez & 0 & 0 & 1 & 0 & \\
\hline Ocotea velutina (Nees) Rohwer & 2 & 1 & 11 & 4 & \\
\hline \multicolumn{6}{|l|}{ LECYTHIDACEAE } \\
\hline Cariniana estrellensis (Raddi) Kuntze & 1 & 0 & 24 & 6 & LR \\
\hline Cariniana legalis (Mart.) Kuntze & 0 & 0 & 0 & 1 & \\
\hline \multicolumn{6}{|l|}{ LOGANIACEAE } \\
\hline Strychnos cf. brasiliensis (Speng.) Mart. & 0 & 2 & 1 & 1 & \\
\hline \multicolumn{6}{|l|}{ LYTHRACEAE } \\
\hline Lafoensia pacari A.St.-Hil. & 0 & 1 & 1 & 0 & \\
\hline
\end{tabular}




\begin{tabular}{|c|c|c|c|c|c|}
\hline \multirow[b]{2}{*}{ Família/Espécie } & \multicolumn{4}{|c|}{ Grupo } & \multirow[t]{2}{*}{$\chi^{2}$} \\
\hline & $\mathrm{P}$ & $\mathrm{C}$ & M & $\mathrm{D}$ & \\
\hline \multicolumn{6}{|l|}{ MAGNOLIACEAE } \\
\hline Michelia champaca $\mathrm{L}$. & 0 & 0 & 1 & 2 & \\
\hline Talauma ovata A.St.-Hil. & 4 & 0 & 1 & 0 & \\
\hline \multicolumn{6}{|l|}{ MALPIGHIACEAE } \\
\hline Byrsonima sp. & 0 & 0 & 1 & 0 & \\
\hline Byrsonima intermedia A.Juss. & 2 & 12 & 4 & 1 & \\
\hline Heteropterys byrsonimifolia A.Juss. & 0 & 7 & 0 & 0 & \\
\hline Heteropterys orinocensis (Kunth) A.Juss. & 1 & 0 & 0 & 0 & \\
\hline \multicolumn{6}{|l|}{ MALVACEAE } \\
\hline Abutilon peltatum K.Schum. & 0 & 0 & 3 & 0 & \\
\hline Bastardiopsis densiflora (Hook. \& Arn.) Hassl. & 0 & 0 & 6 & 3 & \\
\hline Pavonia communis A.St.-Hil. & 0 & 0 & 0 & 1 & \\
\hline Pavonia sepium A.St.-Hil. & 0 & 0 & 1 & 0 & \\
\hline Wissadula subpeltata (Kuntze) R.E.Fr. & 0 & 1 & 0 & 0 & \\
\hline \multicolumn{6}{|l|}{ MELASTOMATACEAE } \\
\hline Clidemia hirta (L.) D.Don & 1 & 1 & 1 & 0 & \\
\hline Leandra regnellii (Triana) Cogn. & 1 & 1 & 0 & 0 & \\
\hline Leandra purpurascens (Schrank \& Mart. ex DC.) Cogn. & 0 & 1 & 1 & 0 & \\
\hline Miconia affinis DC. & 4 & 0 & 8 & 0 & \\
\hline Miconia albicans (Sw.) Triana & 0 & 15 & 3 & 0 & \\
\hline Miconia sp. & 0 & 1 & 0 & 0 & \\
\hline Miconia chamissois Naudin & 4 & 0 & 2 & 0 & \\
\hline Miconia collatata Wurdack & 0 & 1 & 3 & 0 & \\
\hline Miconia discolor DC. & 0 & 0 & 2 & 0 & \\
\hline Miconia langsdorffii Cogn. & 0 & 1 & 0 & 0 & \\
\hline Miconia ligustroides (DC.) Naudin & 0 & 3 & 0 & 0 & \\
\hline Miconia rubiginosa (Bonpl.) DC. & 0 & 3 & 0 & 0 & \\
\hline Miconia sellowiana Naudin & 0 & 1 & 0 & 0 & \\
\hline Miconia stenostachya Schrank \& Mart. ex DC. & 1 & 3 & 1 & 0 & \\
\hline Tibouchina granulosa (Desr.) Cogn. & 0 & 1 & 0 & 0 & \\
\hline Tococa cardiophylla Naudin & 1 & 0 & 0 & 0 & \\
\hline \multicolumn{6}{|l|}{ MELIACEAE } \\
\hline Cabralea cangerana Saldanha & 0 & 0 & 5 & 0 & \\
\hline Cedrela fissilis Vell. & 0 & 1 & 19 & 26 & $\mathrm{LR}, \mathrm{Li}$ \\
\hline Cedrela odorata $\mathrm{L}$ & 4 & 0 & 0 & 2 & \\
\hline Guarea guidonia (L.) Sleumer & 4 & 0 & 22 & 24 & $\mathrm{LR}, \mathrm{Li}$ \\
\hline Guarea kunthiana A.Juss. & 0 & 0 & 10 & 2 & \\
\hline Guarea macrophylla Vahl & 9 & 0 & 7 & 0 & \\
\hline Melia azedarach $\mathrm{L}$. & 0 & 0 & 2 & 5 & \\
\hline Trichilia casaretti C.DC. & 1 & 0 & 22 & 17 & LR \\
\hline Trichilia catigua A.Juss. & 0 & 0 & 20 & 4 & LR \\
\hline Trichilia clausseni C.DC. & 0 & 0 & 19 & 4 & LR \\
\hline Trichilia elegans A.Juss. & 0 & 0 & 7 & 0 & \\
\hline Trichilia hirta $\mathrm{L}$ & 0 & 0 & 8 & 7 & \\
\hline Trichilia pallida $\mathrm{Sw}$. & 1 & 3 & 23 & 6 & LR \\
\hline \multicolumn{6}{|l|}{ MONIMIACEAE } \\
\hline Mollinedia widgrenii A.DC. & 0 & 1 & 11 & 1 & \\
\hline Siparuna cujabana (Mart.) A.DC. & 1 & 0 & 0 & 0 & \\
\hline Siparuna glossostyla Perkins & 0 & 0 & 1 & 0 & \\
\hline Siparuna guianensis Aubl. & 0 & 16 & 12 & 1 & $\begin{array}{l}\text { LV } \\
\text { continua }\end{array}$ \\
\hline
\end{tabular}


continuação

\begin{tabular}{|c|c|c|c|c|c|}
\hline \multirow[b]{2}{*}{ Família/Espécie } & \multicolumn{4}{|c|}{ Grupo } & \multirow[t]{2}{*}{$\chi^{2}$} \\
\hline & $\mathrm{P}$ & $\mathrm{C}$ & M & $\mathrm{D}$ & \\
\hline \multicolumn{6}{|l|}{ MORACEAE } \\
\hline Brosimum gaudichaudii Trécul & 0 & 12 & 1 & 0 & \\
\hline Ficus glabra Willd. & 0 & 0 & 2 & 2 & \\
\hline Ficus guaranitica Chodat & 3 & 6 & 15 & 16 & NS \\
\hline Ficus insipida (Miq.) Miq. & 3 & 0 & 0 & 3 & \\
\hline Ficus cf. obtusifolia Kunth & 0 & 3 & 5 & 1 & \\
\hline Ficus obtusiuscula (Miq.) Miq. & 5 & 0 & 2 & 0 & \\
\hline Ficus tomentella Miq. & 0 & 0 & 1 & 1 & \\
\hline Ficus trigona L.f. & 1 & 0 & 1 & 0 & \\
\hline Maclura tinctoria (L.) D.Don ex Steud. & 1 & 0 & 9 & 25 & $\mathrm{Li}$ \\
\hline Sorocea bonplandii (Baill.) W.C.Burger, Lanj. \& Wess.-Boer & 0 & 0 & 1 & 0 & \\
\hline \multicolumn{6}{|l|}{ MYRISTICACEAE } \\
\hline Virola bicuhyba (Schott ex Spreng.) Warb. & 0 & 1 & 3 & 0 & \\
\hline Virola sebifera Aubl. & 2 & 13 & 11 & 2 & LV \\
\hline \multicolumn{6}{|l|}{ MYRSINACEAE } \\
\hline Ardisia ambigua Mart. & 0 & 0 & 12 & 3 & \\
\hline Ardisia warmingii (Mez) Bernacci \& Jung-Mendançolli & 0 & 1 & 5 & 0 & \\
\hline Cybianthus goyazensis $\mathrm{Mez}$ & 3 & 0 & 0 & 0 & \\
\hline Rapanea balansae $\mathrm{Mez}$ & 0 & 0 & 6 & 0 & \\
\hline Rapanea ferruginea (Ruiz \& Pav.) Mez & 1 & 1 & 0 & 0 & \\
\hline Rapanea gardneriana $\mathrm{Mez}$ & 5 & 0 & 1 & 0 & \\
\hline \multicolumn{6}{|l|}{ MYRTACEAE } \\
\hline Blepharocalyx salicifolius (Kunth) O.Berg & 1 & 0 & 0 & 0 & \\
\hline Calyptranthes clusaefolia (Cambess.) O.Berg & 0 & 1 & 0 & 0 & \\
\hline Calyptranthes widgreniana O.Berg & 1 & 0 & 8 & 0 & \\
\hline Campomanesia adamantium O.Berg & 0 & 2 & 0 & 0 & \\
\hline Campomanesia guazumifolia (Cambess.) O.Berg & 0 & 0 & 2 & 1 & \\
\hline Campomanesia pubescens (DC.) O.Berg & 0 & 1 & 1 & 0 & \\
\hline Campomanesia sp. 1 & 0 & 1 & 0 & 0 & \\
\hline Campomanesia sp. 2 & 0 & 1 & 0 & 0 & \\
\hline Campomanesia xanthocarpa O.Berg & 0 & 1 & 0 & 0 & \\
\hline Eugenia aurata O.Berg & 0 & 5 & 0 & 0 & \\
\hline Eugenia bimarginata DC. & 0 & 8 & 0 & 0 & \\
\hline Eugenia blasthanta (O.Berg) D.Legrand & 0 & 0 & 3 & 0 & \\
\hline Eugenia $\mathrm{cf}$ repanda O.Berg & 0 & 0 & 2 & 0 & \\
\hline Eugenia florida DC. & 8 & 6 & 15 & 8 & NS \\
\hline Eugenia hyemalis Cambess. & 2 & 4 & 8 & 6 & \\
\hline Eugenia involucrata DC. & 0 & 0 & 11 & 1 & \\
\hline Eugenia ligustrina (Sw.) Willd. & 0 & 0 & 1 & 0 & \\
\hline Eugenia moraviana O.Berg & 2 & 0 & 7 & 1 & \\
\hline Eugenia pitanga (O.Berg) Kiaersk. & 0 & 0 & 1 & 0 & \\
\hline Eugenia punicifolia (Kunth) DC. & 0 & 5 & 0 & 0 & \\
\hline Eugenia pyriformis (Desv. ex Ham.) Nied. & 0 & 3 & 0 & 0 & \\
\hline Eugenia sp. 1 & 0 & 0 & 1 & 0 & \\
\hline Eugenia sp. 2 & 0 & 0 & 4 & 1 & \\
\hline Eugenia sp. 3 & 0 & 1 & 8 & 2 & \\
\hline Eugenia sp. 4 & 0 & 0 & 1 & 0 & \\
\hline Eugenia speciosa Cambess. & 0 & 0 & 2 & 0 & \\
\hline Eugenia uniflora $\mathrm{L}$ & 0 & 0 & 0 & 6 & \\
\hline Hexachlamys edulis (O.Berg) Kausel \& D.Legrand & 0 & 0 & 4 & 6 & \\
\hline
\end{tabular}




\begin{tabular}{|c|c|c|c|c|c|}
\hline \multirow[b]{2}{*}{ Família/Espécie } & \multicolumn{4}{|c|}{ Grupo } & \multirow[t]{2}{*}{$\chi^{2}$} \\
\hline & $\mathrm{P}$ & $\mathrm{C}$ & M & $\mathrm{D}$ & \\
\hline Myrceugenia cf. foveolata (O.Berg) Sobral & 1 & 0 & 0 & 0 & \\
\hline Myrcia aff. pubescens Humb. \& Bonpl. ex Willd. & 2 & 0 & 0 & 0 & \\
\hline Myrcia laruotteana Cambess. & 4 & 0 & 0 & 0 & \\
\hline Myrcia lingua (O.Berg) Mattos \& D.Legrand & 0 & 10 & 2 & 0 & \\
\hline Myrcia richardiana (O.Berg) Kiaersk. & 0 & 2 & 0 & 0 & \\
\hline Myrcia rufipes DC. & 0 & 1 & 1 & 0 & \\
\hline Myrcia tomentosa (Aubl.) DC. & 2 & 5 & 4 & 2 & \\
\hline Myrcia uberavensis O.Berg & 0 & 4 & 0 & 0 & \\
\hline Myrcia venulosa DC. & 0 & 1 & 0 & 0 & \\
\hline Myrcianthes pungens (O.Berg) D.Legrand & 1 & 0 & 3 & 0 & \\
\hline Myrciaria floribunda (H.West ex Willd.) O.Berg & 0 & 3 & 7 & 1 & \\
\hline Myrciaria glazioviana (Kiaersk.) G.Barroso ex Sobral & 0 & 0 & 1 & 0 & \\
\hline Myrtaceae sp. & 1 & 0 & 0 & 0 & \\
\hline Plinia cauliflora (DC.) Kausel & 0 & 1 & 3 & 6 & \\
\hline Psidium cf. sartorianum (O.Berg) Nied. & 0 & 0 & 4 & 2 & \\
\hline Psidium guajava $\mathrm{L}$. & 1 & 0 & 6 & 12 & \\
\hline Psidium rufum DC. & 0 & 3 & 0 & 0 & \\
\hline Psidium sp. 1 & 0 & 0 & 1 & 0 & \\
\hline Psidium sp. 2 & 0 & 0 & 2 & 0 & \\
\hline Psidium suffruticosum O.Berg & 0 & 1 & 0 & 0 & \\
\hline Syzygium cumini (L.) Skeels & 2 & 0 & 1 & 3 & \\
\hline Syzygium jambos (L.) Alston & 2 & 1 & 4 & 4 & \\
\hline \multicolumn{6}{|l|}{ NYCTAGINACEAE } \\
\hline Guapira hirsuta (Choisy) Lundell & 2 & 0 & 9 & 5 & \\
\hline Guapira noxia (Netto) Lundell & 0 & 5 & 2 & 0 & \\
\hline Guapira opposita (Vell.) Reitz & 0 & 0 & 8 & 3 & \\
\hline Pisonia aculeata $\mathrm{L}$ & 0 & 0 & 1 & 0 & \\
\hline Pisonia ambigua Heimerl & 0 & 0 & 0 & 1 & \\
\hline \multicolumn{6}{|l|}{ OCHNACEAE } \\
\hline Ouratea castaneifolia (DC.) Engl. & 1 & 5 & 6 & 1 & \\
\hline Ouratea spectabilis (Mart. ex Engl.) Engl. & 0 & 5 & 0 & 0 & \\
\hline \multicolumn{6}{|l|}{ ONAGRACEAE } \\
\hline Ludwigia laruotteana (Cambess.) H.Hara & 2 & 0 & 0 & 1 & \\
\hline Ludwigia nervosa (Poir.) H.Hara & 0 & 0 & 0 & 1 & \\
\hline \multicolumn{6}{|l|}{ OPILIACEAE } \\
\hline Agonandra brasiliensis Miers ex Benth. \& Hook.f. & 0 & 1 & 5 & 0 & \\
\hline \multicolumn{6}{|l|}{ PHYTOLACCACEAE } \\
\hline Gallesia integrifolia (Spreng.) Harms & 0 & 0 & 11 & 8 & LR \\
\hline Seguieria americana $\mathrm{L}$. & 0 & 0 & 2 & 1 & \\
\hline \multicolumn{6}{|l|}{ PIPERACEAE } \\
\hline Ottonia propinqua Miq. & 0 & 0 & 2 & 0 & \\
\hline Piper aduncum L. & 5 & 0 & 12 & 19 & LR \\
\hline Piper amalago L. & 1 & 0 & 17 & 21 & LR \\
\hline Piper amplum Kunth & 0 & 0 & 1 & 0 & \\
\hline Piper arboreum Aubl. & 5 & 2 & 12 & 7 & LR \\
\hline Piper fuligineum Kunth & 1 & 0 & 0 & 0 & \\
\hline Piper glabratum Kunth & 0 & 0 & 6 & 12 & \\
\hline Piper hispidum Sw. & 0 & 0 & 1 & 0 & \\
\hline Piper mollicomum Kunth & 2 & 0 & 4 & 0 & \\
\hline Piper solmsianum C.DC. & 0 & 0 & 1 & 0 & \\
\hline
\end{tabular}


continuação

\begin{tabular}{|c|c|c|c|c|c|}
\hline \multirow[b]{2}{*}{ Família/Espécie } & \multicolumn{4}{|c|}{ Grupo } & \multirow[t]{2}{*}{$\chi^{2}$} \\
\hline & $\mathrm{P}$ & $\mathrm{C}$ & M & $\mathrm{D}$ & \\
\hline \multicolumn{6}{|l|}{ PODOCARPACEAE } \\
\hline Podocarpus sellowii Klotzsch ex Eichler & 1 & 0 & 0 & 0 & \\
\hline \multicolumn{6}{|l|}{ POLIGONACEAE } \\
\hline Triplaris americana $\mathrm{L}$. & 0 & 0 & 1 & 2 & \\
\hline \multicolumn{6}{|l|}{ POLYGALACEAE } \\
\hline Bredemeyra floribunda Willd. & 0 & 3 & 5 & 1 & \\
\hline \multicolumn{6}{|l|}{ PROTEACEAE } \\
\hline Roupala montana Aubl. & 1 & 11 & 10 & 0 & LV \\
\hline \multicolumn{6}{|l|}{ RHAMNACEAE } \\
\hline Colubrina glandulosa Perkins & 0 & 0 & 2 & 1 & \\
\hline Rhamnidium elaeocarpum Reissek & 2 & 0 & 20 & 28 & $\mathrm{LR}, \mathrm{Li}$ \\
\hline \multicolumn{6}{|l|}{ ROSACEAE } \\
\hline Prunus myrtifolia (L.) Urb. & 0 & 1 & 2 & 0 & \\
\hline \multicolumn{6}{|l|}{ RUBIACEAE } \\
\hline Alibertia macrophylla K.Schum. & 0 & 13 & 13 & 0 & LV \\
\hline Amaioua intermedia Mart. & 0 & 2 & 2 & 0 & \\
\hline Chomelia bella (Stand1.) Steyerm. & 0 & 0 & 6 & 16 & $\mathrm{LR}, \mathrm{Li}$ \\
\hline Chomelia obtusa Cham. \& Schltdl. & 0 & 1 & 2 & 2 & \\
\hline Chomelia pohliana Müll.Arg. & 2 & 0 & 3 & 1 & \\
\hline Coffea arabica $\mathrm{L}$ & 0 & 0 & 8 & 6 & \\
\hline Coussarea contracta (Walp.) Müll.Arg. & 0 & 2 & 1 & 0 & \\
\hline Coussarea hydrangeifolia (Benth.) Müll.Arg. & 0 & 6 & 5 & 0 & \\
\hline Coutarea hexandra (Jacq.) K.Schum. & 0 & 1 & 5 & 8 & \\
\hline Faramea montevidensis (Cham. \& Schltdl.) DC. & 0 & 0 & 3 & 0 & \\
\hline Genipa americana $\mathrm{L}$ & 4 & 0 & 14 & 15 & LR \\
\hline Guettarda pohliana Müll.Arg. & 1 & 0 & 3 & 6 & \\
\hline Guettarda viburnoides Cham. \& Schltdl. & 0 & 1 & 2 & 0 & \\
\hline Hamelia patens Jacq. & 0 & 0 & 0 & 1 & \\
\hline Ixora brevifolia Benth. & 0 & 0 & 6 & 0 & \\
\hline Ixora heterodoxa Müll.Arg. & 0 & 0 & 3 & 0 & \\
\hline Palicourea croceoides Desv. ex Ham & 6 & 0 & 2 & 0 & \\
\hline Palicourea macrobotrys (Ruiz \& Pav.) Roem. \& Schult. & 0 & 0 & 1 & 0 & \\
\hline Palicourea marcgravii A.St.-Hil. & 0 & 0 & 1 & 0 & \\
\hline Palicourea rigida Kunth & 0 & 1 & 0 & 0 & \\
\hline Posoqueira latifolia K.Krause & 1 & 0 & 0 & 0 & \\
\hline Psychotria capitata Ruiz \& Pav. & 1 & 3 & 0 & 0 & \\
\hline Psychotria carthagenensis Jacq. & 8 & 0 & 10 & 15 & $\mathrm{Hi}$ \\
\hline Psychotria cephalantha (Müll.Arg.) Standl. & 0 & 1 & 5 & 0 & \\
\hline Psychotria deflexa DC. & 0 & 1 & 1 & 0 & \\
\hline Psychotria hoffmannseggiana (Willd. ex Roem. \& Schult.) Müll.Arg. & 0 & 2 & 0 & 0 & \\
\hline Psychotria sciaphila S.Moore & 0 & 3 & 0 & 0 & \\
\hline Psychotria sp. & 0 & 0 & 2 & 0 & \\
\hline Randia armata (Sw.) DC. & 0 & 0 & 3 & 9 & \\
\hline Rudgea jasminoides (Cham.) Müll.Arg. & 0 & 0 & 2 & 0 & \\
\hline Rudgea sp. & 0 & 0 & 1 & 0 & \\
\hline Rudgea viburnoides (Cham.) Benth. & 0 & 3 & 1 & 0 & \\
\hline Simira sampaioana (Standl.) Steyerm. & 0 & 0 & 7 & 4 & \\
\hline Tocoyena formosa (Cham. \& Schltdl.) K. Schum. & 0 & 12 & 2 & 1 & \\
\hline \multicolumn{6}{|l|}{ RUTACEAE } \\
\hline Conchocarpus pentandrus (A.St.-Hil.) Kallunki \& Pirani & 0 & 0 & 1 & 0 & \\
\hline
\end{tabular}




\begin{tabular}{|c|c|c|c|c|c|}
\hline \multirow[b]{2}{*}{ Família/Espécie } & \multicolumn{4}{|c|}{ Grupo } & \multirow[t]{2}{*}{$\chi^{2}$} \\
\hline & $\mathrm{P}$ & $\mathrm{C}$ & M & $\mathrm{D}$ & \\
\hline Esenbeckia febrifuga (A.St.-Hil.) A.Juss. ex Mart. & 0 & 0 & 3 & 5 & \\
\hline Galipea jasminiflora (A.St.-Hil.) Engl. & 0 & 0 & 18 & 1 & \\
\hline Metrodorea nigra A.St.-Hil. & 0 & 0 & 16 & 1 & \\
\hline Murraya exótica $\mathrm{L}$. & 0 & 0 & 0 & 3 & \\
\hline Pilocarpus pauciflorus A.St.-Hil. & 0 & 0 & 1 & 0 & \\
\hline Pilocarpus pennatifolius Lem. & 0 & 0 & 8 & 0 & \\
\hline Zanthoxylum sp. & 0 & 0 & 2 & 0 & \\
\hline Zanthoxylum acuminatum (Sw.) Sw. & 0 & 0 & 2 & 0 & \\
\hline Zanthoxylum caribaeum Lam. & 0 & 0 & 2 & 1 & \\
\hline Zanthoxylum fagara A.St.-Hil. & 0 & 0 & 3 & 1 & \\
\hline Zanthoxylum monogynum Poepp. & 0 & 0 & 2 & 0 & \\
\hline Zanthoxylum petiolare A.St.-Hil. \& Tul. & 0 & 0 & 4 & 3 & \\
\hline Zanthoxylum rhoifolium Lam. & 0 & 2 & 14 & 15 & NS \\
\hline Zanthoxylum riedelianum Engl. & 4 & 2 & 9 & 14 & NS \\
\hline \multicolumn{6}{|l|}{ SAPINDACEAE } \\
\hline Allophylus edulis (A.St.-Hil., Cambess. \& A.Juss.) Radlk. & 0 & 0 & 7 & 1 & \\
\hline Allophylus sericeus Radlk. & 2 & 0 & 22 & 24 & $\mathrm{LR}, \mathrm{Li}$ \\
\hline Cupania vernalis Cambess. & 5 & 8 & 21 & 5 & LR,LV \\
\hline Diatenopteryx sorbifolia Radlk. & 0 & 0 & 2 & 0 & \\
\hline Dilodendron bipinnatum Radlk. & 1 & 0 & 4 & 10 & \\
\hline Dimocarpus longan Lour. & 0 & 0 & 0 & 1 & \\
\hline Matayba elaeagnoides Radlk. & 1 & 3 & 9 & 3 & \\
\hline \multicolumn{6}{|l|}{ SAPOTACEAE } \\
\hline Chrysophyllum gonocarpum (Mart. \& Eichler) Engl. & 0 & 0 & 15 & 8 & LR \\
\hline Chrysophyllum marginatum (Hook. \& Arn.) Radlk. & 2 & 1 & 9 & 10 & NS \\
\hline Pouteria caimito (Ruiz \& Pav.) Radlk. & 0 & 0 & 1 & 0 & \\
\hline Pouteria gardneri (Mart. \& Miq.) Baehni & 0 & 0 & 3 & 1 & \\
\hline Pouteria ramiflora (Mart.) Radlk. & 0 & 14 & 6 & 0 & LV \\
\hline Pouteria torta (Mart.) Radlk. & 0 & 3 & 1 & 0 & \\
\hline \multicolumn{6}{|l|}{ SIMAROUBACEAE } \\
\hline Picramnia sellowii Planch. & 4 & 1 & 6 & 0 & \\
\hline \multicolumn{6}{|l|}{ SOLANACEAE } \\
\hline Brunfelsia pauciflora (Cham. \& Schltdl.) Benth. & 0 & 0 & 1 & 1 & \\
\hline Cestrum corymbosum Schltdl. & 2 & 5 & 1 & 5 & \\
\hline Cestrum lanceolatum Miers & 0 & 0 & 1 & 0 & \\
\hline Cestrum schlechtendalli G.Don & 2 & 0 & 0 & 0 & \\
\hline Cestrum strigilatum Ruiz \& Pav. & 0 & 0 & 2 & 6 & \\
\hline Solanum argenteum Dunal & 0 & 0 & 6 & 0 & \\
\hline Solanum cernuum Vell. & 1 & 0 & 0 & 0 & \\
\hline Solanum concinuum Sendtn. & 0 & 0 & 5 & 3 & \\
\hline Solanum granuloso-leprosum A.St.-Hil. & 2 & 1 & 9 & 13 & NS \\
\hline Solanum lycocarpum Dunal & 0 & 3 & 0 & 0 & \\
\hline Solanum oocarpum Sendtn. & 0 & 0 & 1 & 1 & \\
\hline Solanum paniculatum Dunal & 1 & 5 & 1 & 7 & \\
\hline Solanum pseudoquina A.St.-Hil. & 0 & 0 & 1 & 1 & \\
\hline Solanum variabile Mart. & 1 & 0 & 1 & 2 & \\
\hline \multicolumn{6}{|l|}{ STERCULIACEAE } \\
\hline Guazuma ulmifolia Lam. & 1 & 1 & 16 & 19 & $\mathrm{LR}, \mathrm{Li}$ \\
\hline Helicteris brevispira A.St.-Hil. & 0 & 0 & 1 & 0 & \\
\hline
\end{tabular}


continuação

\begin{tabular}{|c|c|c|c|c|c|}
\hline \multirow[b]{2}{*}{ Família/Espécie } & \multicolumn{4}{|c|}{ Grupo } & \multirow[t]{2}{*}{$\chi^{2}$} \\
\hline & $\mathrm{P}$ & $\mathrm{C}$ & $\mathrm{M}$ & $\mathrm{D}$ & \\
\hline \multicolumn{6}{|l|}{ STYRACACEAE } \\
\hline Styrax camporum Pohl & 0 & 2 & 1 & 0 & \\
\hline Styrax ferrugineus Nees \& Mart. & 0 & 2 & 0 & 0 & \\
\hline Styrax pohlii A.DC. & 6 & 1 & 6 & 0 & \\
\hline \multicolumn{6}{|l|}{ THEOPHRASTACEAE } \\
\hline Clavija nutans (Vell.) B.Stahl & 1 & 0 & 9 & 4 & \\
\hline \multicolumn{6}{|l|}{ THYMELAEACEAE } \\
\hline Daphnopsis gemmiflora (Miers) Domke & 1 & 0 & 1 & 0 & \\
\hline Daphnopsis racemosa Griseb. & 2 & 0 & 1 & 0 & \\
\hline \multicolumn{6}{|l|}{ TILIACEAE } \\
\hline Christiania macrodon Toledo & 0 & 0 & 6 & 0 & \\
\hline Heliocarpus americanus L. & 0 & 0 & 2 & 0 & \\
\hline Luehea candicans Mart. & 0 & 0 & 0 & 1 & \\
\hline Luehea divaricata Mart. & 3 & 0 & 9 & 11 & NS \\
\hline Luehea grandiflora Mart. & 1 & 9 & 5 & 7 & NS \\
\hline Muntingia calabura $\mathrm{L}$. & 0 & 0 & 1 & 0 & \\
\hline Triumfetta semitriloba Jacq. & 1 & 0 & 0 & 0 & \\
\hline \multicolumn{6}{|l|}{ ULMACEAE } \\
\hline Celtis brasiliense (Gardner) Planch. & 0 & 0 & 2 & 0 & $\mathrm{LR}, \mathrm{Li}$ \\
\hline Celtis iguanea (Jacq.) Sarg. & 2 & 3 & 20 & 33 & \\
\hline Trema micrantha (L.) Blume & 3 & 2 & 11 & 17 & NS \\
\hline \multicolumn{6}{|l|}{ URTICACEAE } \\
\hline Urera baccifera (L.) Gaudich. ex Wedd. & 2 & 0 & 13 & 17 & LR \\
\hline \multicolumn{6}{|l|}{ VERBENACEAE } \\
\hline Aegiphila klotzkiana Cham. & 0 & 7 & 1 & 1 & \\
\hline Aegiphila sellowiana Cham. & 1 & 8 & 13 & 9 & LV \\
\hline Aloysia virgata (Ruiz \& Pav.) Juss. & 1 & 0 & 13 & 26 & $\mathrm{LR}, \mathrm{Li}$ \\
\hline Citharexyllum myrianthum Cham. & 0 & 0 & 0 & 1 & \\
\hline Lantana brasiliense Link & 0 & 1 & 1 & 1 & \\
\hline Lantana camara $\mathrm{L}$. & 0 & 0 & 0 & 1 & \\
\hline Vitex polygama Cham. & 0 & 2 & 1 & 0 & \\
\hline \multicolumn{6}{|l|}{ VIOLACEAE } \\
\hline Hybanthus atropurpureus (A.St.-Hil.) Taub. & 0 & 1 & 8 & 2 & \\
\hline \multicolumn{6}{|l|}{ VOCHYSIACEAE } \\
\hline Qualea cordata (Mart.) Spreng. & 0 & 1 & 0 & 0 & \\
\hline Qualea grandiflora Mart. & 0 & 12 & 0 & 0 & \\
\hline Qualea jundiahy Warm. & 0 & 4 & 2 & 0 & \\
\hline Qualea multiflora Mart. & 0 & 9 & 3 & 0 & \\
\hline Vochysia tucanorum Mart. & 1 & 6 & 2 & 0 & \\
\hline
\end{tabular}

particularmente na época mais seca do ano, quando a vegetação perde totalmente as folhas. Uma característica fisionômica marcante deste subgrupo é a elevada dominância de Myracrodruon urundeuva e Anandenanthera macrocarpa. Embora não tenha sido registrada a densidade das espécies, a elevada abundância destas duas espécies foi observada no campo. Este subgrupo, denominado de mata decídua (D), foi formado por 35 fragmentos. Foram registradas 259 espécies, dentre as quais 18 eram exóticas. Apenas oito espécies $(3,0 \%)$ ocorreram em mais de $75 \%$ das áreas, e 46,2\% ocorreram em dois ou menos fragmentos, com 95 ocorrências únicas.

O segundo grupo reuniu 16 fragmentos, situados sobre Latossolo Vermelho Escuro e Latossolo Vermelho Amarelo. Apresentou fisionomia florestal, com 
ocorrência conspícua de espécies de cerrado, que caracterizaram a fisionomia denominada cerradão (C). Neste grupo foram registradas 219 espécies, sendo duas exóticas. A maioria das espécies ocorreu em poucos fragmentos $(51,4 \%)$. Dezessete espécies ocorreram em mais de $75 \%$ dos fragmentos e não foram encontradas espécies com ocorrência exclusiva sobre Latossolo Vermelho Escuro ou Latossolo Vermelho Amarelo.

O terceiro grupo reuniu 10 fragmentos de vegetação que ocorreram sobre solos Hidromórficos, associados a cursos d'água. Neste ambiente, o solo permanece encharcado mesmo durante a época seca. Essa formação apresentou árvores muito próximas entre si, altas, e em geral com diâmetro pequeno. Neste grupo foram encontradas 161 espécies, das quais quatro eram exóticas. A maioria das espécies ocorreu em poucos fragmentos, sendo que $40,4 \%$ ocorreram em apenas um fragmento, e 24,2\% foram registradas em apenas dois fragmentos de matas paludícolas. Dentre as espécies comuns, apenas oito ocorreram em mais de $75 \%$ dos fragmentos. Algumas

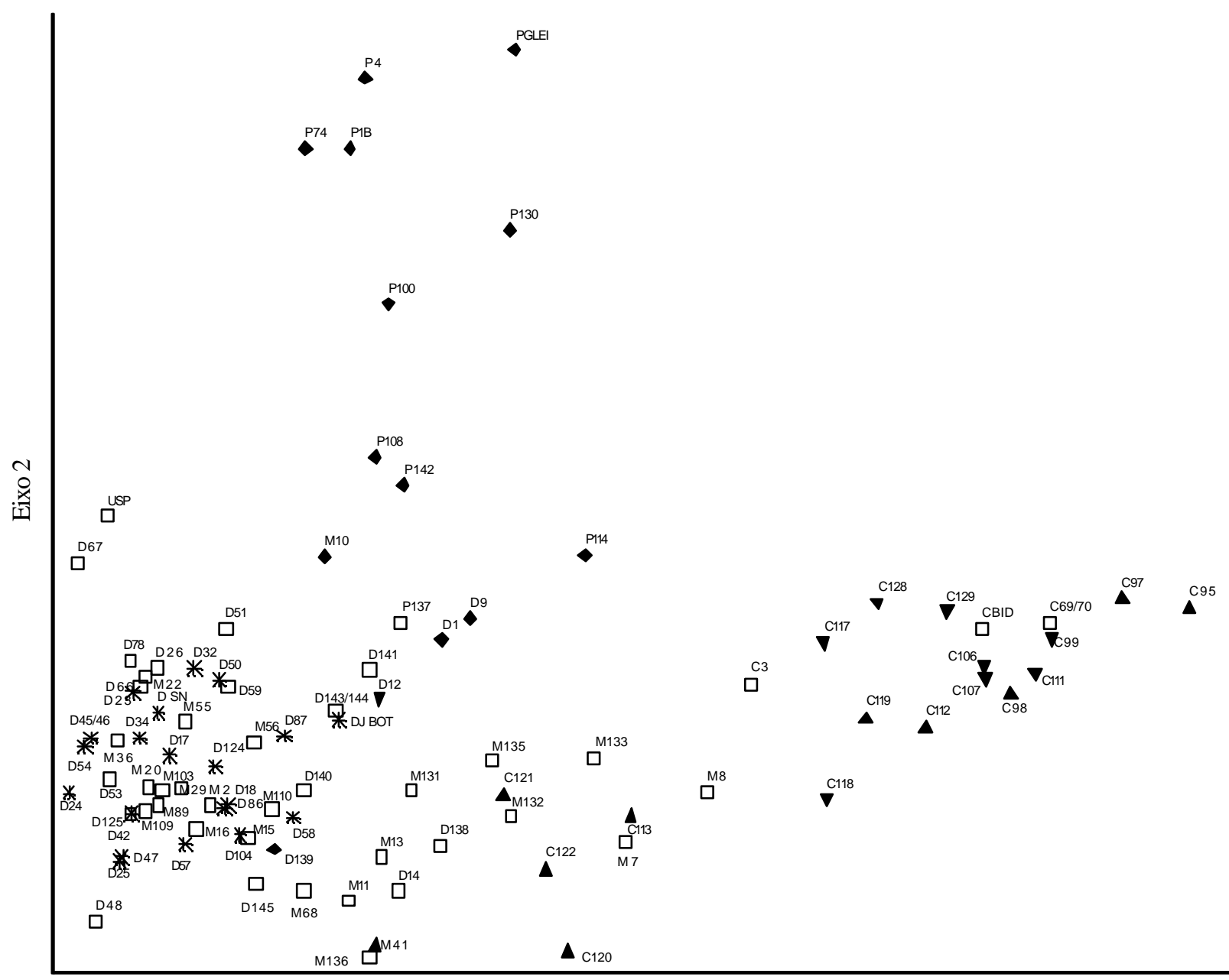

Eixo 1

Figura 2. Diagrama de ordenação dos fragmentos de vegetação natural em Ribeirão Preto, obtido através de análise de correspondência retificada (DCA). $\square=$ Latossolo Roxo, $\boldsymbol{\Delta}=$ Latossolo Vermelho Escuro, $\boldsymbol{\nabla}=$ Latossolo Vermelho Amarelo, $*=$ Litossolo, $\bullet=$ Solo Hidromórfico. As letras junto aos números indicam o tipo de vegetação: $\mathrm{C}=$ cerradão, $\mathrm{D}=$ mata decídua, $\mathrm{M}=$ mata mesófila, $\mathrm{P}$ = mata paludícola.

Figure 2. Ordination diagram, of the natural vegetation fragments in Ribeirão Preto, obtained by detrended corresponde analisys (DCA). $\square=$ Purple Latosol, $\boldsymbol{\Delta}=$ Dark Red Latosol, $\boldsymbol{\nabla}=$ Red Yellow Latosol, $*=$ Lythosol, $\bullet=$ Hydromorfic soil. The letters besides the numbers indicate the vegetation tipe: $\mathrm{C}=$ "cerradão", $\mathrm{D}=$ deciduous forest, $\mathrm{M}=$ mesophilous forest, $\mathrm{P}=$ swamp forest. 


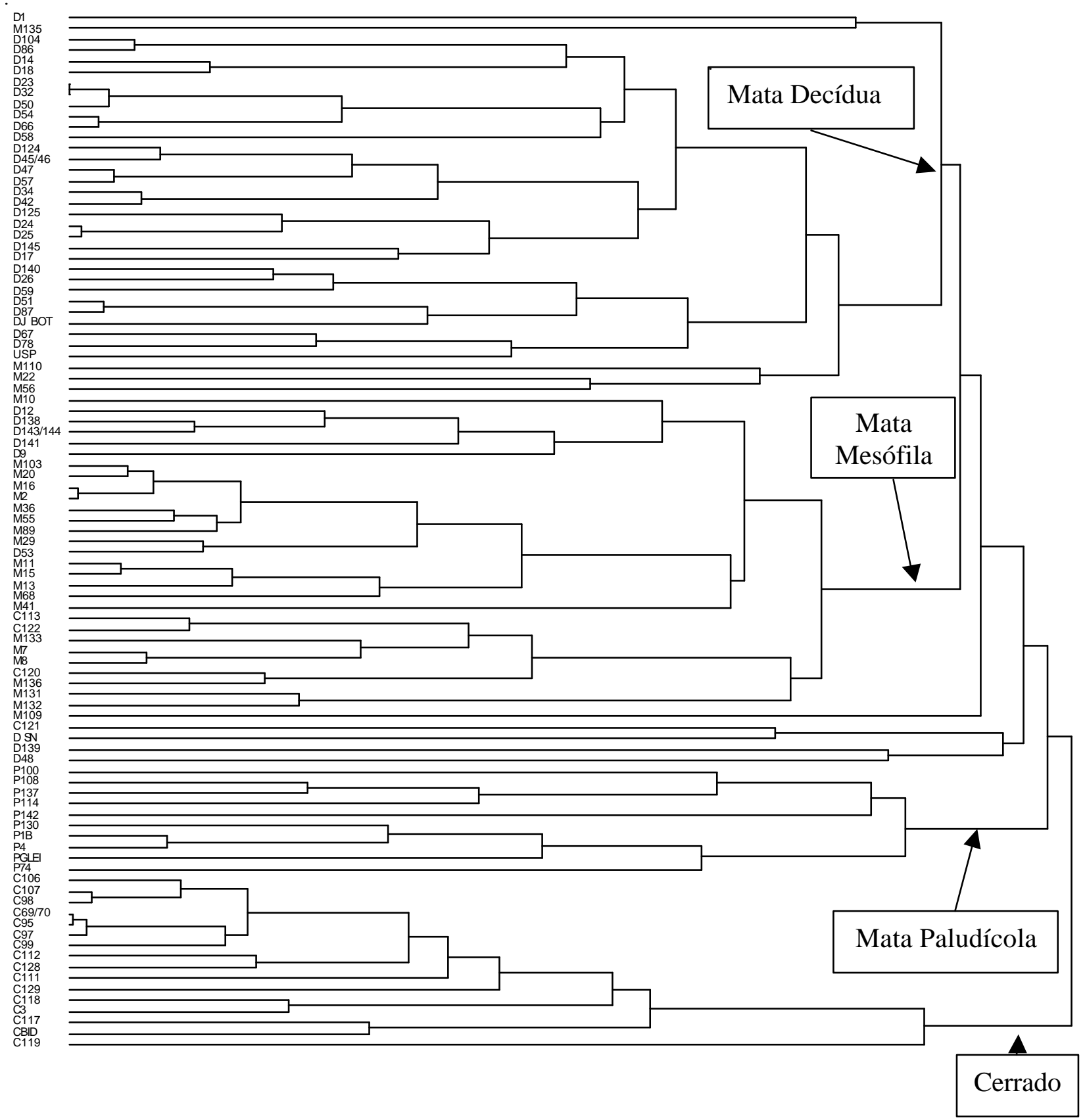

Figura 3. Análise de agrupamento, usando a distância relativa de Sørensen e UPGMA (Unweighted-Pair Groups Method using Arithmetic Averages), dos fragmentos de vegetação natural em Ribeirão Preto, SP. Os fragmentos estão identificados de acordo com o grupo: $\mathrm{C}=$ cerradão, $\mathrm{D}=$ mata decídua, $\mathrm{M}=$ mata mesófila, $\mathrm{P}=$ mata paludícola.

Figure 3. Cluster analysis, using Sørensen relative distance and the Unweighted-Pair Groups Method using Arithmetic Averages (UPGMA), of the native vegetation fragments in Ribeirão Preto, SP. The fragments are identified according to groups: $\mathrm{C}=$ "cerradão", $\mathrm{D}=$ decidous forest, $\mathrm{M}=$ mesophilous forest, $\mathrm{P}=$ swamp forest. 
espécies ocorreram exclusivamente nestas áreas: Hedyosmum brasiliense (Chloranthaceae), Citronella gongonha (Icacinaceae), Myrcia laruoettana (Myrtaceae) e Cybianthus goyazensis (Myrsinaceae).

As matas mesófilas semidecíduas atualmente ocupam apenas $1,4 \%$ do município $(35,2 \%$ da vegetação natural atual). Os cerrados hoje estão reduzidos a $0,8 \%$ da área do município (21,3\% da vegetação natural atual). As matas paludícolas estão reduzidas a $0,6 \%$ da área do município e a $16,4 \%$ da vegetação natural atual. As matas decíduas hoje estão reduzidas a $1,1 \%$ da área do município e a $27,1 \%$ da vegetação natural atual.

Entre as espécies nativas encontradas, 79 foram registradas em mais de 20 fragmentos. Destas espécies, 27 (34,2\%) apresentaram distribuição não preferencial por nenhum tipo de solo, e $52(65,8 \%)$ apresentaram distribuição que sugere preferência por algum tipo de solo.

Entre as espécies que apresentaram preferência por algum tipo de solo, 20 foram mais freqüentes que o esperado em Latossolo Roxo, 11 em Latossolo Roxo e Litossolo, 14 em Latossolo Vermelho, três em Litossolo e três em solo Hidromórfico (tabela 1). Entre estas, 13 espécies não ocorreram sobre solo Hidromórfico, 22 sobre Latossolo Vermelho, e duas não ocorreram sobre Litossolo. Cupania vernalis ocorreu em freqüência maior que o esperado em Latossolo Roxo e Latossolo Vermelho.

\section{Discussão}

Outros métodos de análise multivariada foram testados e apresentaram resultados semelhantes, com o mesmo padrão na formação dos grupos. Análises deste tipo, baseadas em dados de densidade, dominância e frequiência das espécies, devem apresentar resultados mais acurados, mas parece improvável que resultem em grupos com outras características que as apresentadas.

A ocorrência de grupos florísticos distintos, indicada nas análises de ordenação, classificação e na análise de permutação, podem ser associados às classes de solo existentes (mata mesófila semidecídua - Latossolo Roxo, mata decídua - Litossolo, mata paludícola - Solos Hidromórficos, cerrado - Latossolo Vermelho Escuro e Latossolo Vermelho Amarelo).

Diversos trabalhos descreveram associação semelhante (Johnston 1992, Felfili \& Silva Júnior 1993, Felfili et al. 1998, Oliveira Filho et al. 1994a, Salis et al. 1995, Clark et al. 1995, 1998, 1999, Swaine 1996, Torres et al. 1997, Ribeiro \& Walter 1998). Baseados em dados quantitativos de espécies arbóreas que ocorrem dentro de uma mesma formação florestal, alguns autores identificaram gradientes associados às variações nas características pedológicas (Oliveira Filho et al. 1994a, b, Bertani et al. 2001, Botrel et al. 2002). Estas associações sugerem a possibilidade de inferir a composição florística a partir do tipo de solo e aplicar este conhecimento na restauração das formações.

Os grupos formados pelas matas paludícolas, pelos cerradões e pelas matas foram bem separados. As matas mesófilas semidecíduas e matas decíduas foram melhor descritas como subgrupos, visto que apresentaram elevada similaridade florística. Entretanto, apresentaram fisionomias distintas, marcadas pela elevada dominância que ocorre nas matas decíduas e pela diferença no grau de deciduidade das folhas. As matas decíduas, de forma geral, apresentaram menor diversidade de espécies. A menor riqueza de espécies de espécies observada em alguns fragmentos situados sobre Latossolo Roxo, possível reflexo da fragmentação e do isolamento (Turner 1989, Turner \& Corlett 1996, Metzger 1999) ou de outras perturbações, pode estar influenciando na distinção entre matas mesófilas semidecíduas e matas decíduas. Análises efetuadas considerando a abundância das espécies devem evidenciar melhor a separação entre estes subgrupos.

Mais de 65\% das espécies analisadas apresentaram ocorrência significativamente associada com algum tipo de solo, indicando que as características pedológicas têm influência na sua distribuição.

Das espécies mais freqüentes em Latossolo Roxo, várias foram também freqüentes em Litossolo. Tanto Latossolo Roxo como Litossolo são formados a partir da mesma rocha, o basalto. O Latossolo Roxo apresenta horizonte B espesso e homogêneo, enquanto o Litossolo caracteriza-se por ser pouco desenvolvido, com horizonte $\mathrm{B}$ incipiente ou ausente. Há também diferença na localização destes solos, sendo que os Litossolos ocorrem geralmente nos topos dos morros ou locais que apresentam afloramento rochoso. A transição entre estes solos é gradual e ambos podem coexistir muito próximos entre si (base e topo do mesmo morro, p.ex.). A menor profundidade e elevada pedregosidade do solo limitam a agricultura e podem ser fatores limitantes ao estabelecimento de algumas espécies nativas. A dificuldade em delimitar os subgrupos de matas decíduas e mesófilas pode também estar associada ao gradiente destas características em diferentes posições do relevo. Segundo Oliveira Filho \& Ratter (2002), não existem diferenças ecológicas e florísticas claras entre as matas 
decíduas e semidecíduas que ocorrem no Bioma do Cerrado.

Dentre as espécies citadas por Oliveira Filho \& Ratter (2000, 2002) como generalistas por habitat e comuns em matas ciliares, Tapirira guianensis, Copaifera langsdorffii e Virola sebifera apresentaram distribuição preferencial em Latossolo Vermelho Escuro ou Latossolo Vermelho Amarelo, e Didymopanax morototoni e Casearia sylvestris não apresentaram preferência por solo. As espécies citadas estão entre as que ocorreram em maior número de fragmentos e em todos os tipos de solo.

As matas paludícolas foram os fragmentos que apresentaram menor riqueza média de espécies. Estas formações apresentam composição florística distinta e característica, geralmente com reduzido número de espécies (Leitão Filho 1982, 1987, Torres et al. 1994, Ivanauskas et al. 1997), características associadas à saturação hídrica do solo, ambiente que poucas espécies toleram (Joly 1991).

Atualmente, é amplamente aceito que o clima, o tipo de solo e a ocorrência de fogo são os fatores ambientais mais importantes na determinação da distribuição da vegetação de cerrado (Oliveira Filho \& Ratter 2002). No Estado de São Paulo, ocorre extensão da vegetação de cerrado, principalmente na região centro-norte, incluindo o Município de Ribeirão Preto. No município, foi identificada a ocorrência de cerradão, associada com Latossolo Vermelho Escuro e Vermelho Amarelo. Na classificação das fitofisionomias de cerrado apresentada por Ribeiro \& Walter (1998), o cerradão está associado a estes tipos de solo. Muitas das espécies indicadas por estes autores como típicas da formação foram encontradas em Ribeirão Preto.

A associação observada entre solo e composição florística dos remanescentes de vegetação indica que o tipo de solo é um fator importante na determinação da formação vegetal que ocorre no local. Baseado nesta associação, pode-se afirmar que as formações mais afetadas por desmatamentos em Ribeirão Preto foram as matas mesófila semidecíduas e os cerradões.

A maioria dos fragmentos de vegetação analisados estão indicados no Atlas do Programa Biota/Fapesp como vegetação secundária. Estes fragmentos, independente do tamanho ou estado de conservação, foram reunidos em diferentes grupos, indicando que a afinidade florística com o grupo ao qual pertencem é mantida apesar das perturbações sofridas. Estas áreas apresentam espécies típicas das respectivas formações, e são importantes na manutenção da conectividade entre diferentes fragmentos. (Turner 1989, Turner \& Corlett 1996, Metzger et al. 1998, Metzger 1999).

A elevada porcentagem de espécies que ocorrem em poucos fragmentos é característica comum. Os levantamentos florísticos e fitossociológicos realizados, em geral, registram pequeno número de espécies comuns e muitas espécies raras (Cavassan et al. 1984, César \& Leitão Filho 1990, Martins 1991, Ratter et al. 2001). A possibilidade de cada fragmento abrigar espécie(s) com ocorrência restrita é, portanto, elevada, indicando que todos são importantes para a conservação, independente de seu tamanho e estado de conservação.

Os resultados contribuem para o estabelecimento de critérios visando o embasamento das estratégias de conservação adotadas por órgãos e entidades locais e regionais. É possível indicar uma lista de espécies a ser utilizada em plantios em cada região do município baseada no tipo de solo do local. As áreas mais afetadas pelos efeitos dos desmatamentos, e aquelas que apresentam elevada diversidade, no caso, as matas mesófilas semidecíduas e os cerradões, devem ser priorizadas em ações para recuperação e conservação. Os dados apresentados mostram que os fragmentos com vegetação secundária abrigam uma parcela significativa da diversidade de espécies, e devem ser conservados, requerendo ações para o enriquecimento da flora e interligação com outros remanescentes. As formações presentes em áreas ribeirinhas, consideradas de preservação permanente, constituem corredores naturais de dispersão, devendo ser priorizadas na preservação e recuperação. O planejamento de ações visando restauração florestal e o aumento da conectividade entre os remanescentes deve levar em consideração todas as fisionomias descritas.

Agradecimentos - Este trabalho foi financiado pela Fundação de Amparo à Pesquisa do Estado de São Paulo, Fapesp (Processo 98/05117-1), no âmbito do Programa Biota/Fapesp - O Instituto Virtual da Biodiversidade (www.biota.org.br) e por meio de bolsa concedida ao primeiro autor (Processo 99/11347-2). Agradecemos a Giselda Durigan e às sugestões e comentários apresentados por Alexandre A. de Oliveira e por revisores(as) anônimos(as). Carlos A. Joly agradece ao CNPq pela bolsa de Produtividade em Pesquisa (Processo 520334/99-0). Agradecemos também aos Profs. Drs. Marcos Sobral, Sigrid Luiza Jung-Mendonçalli, Inês Cordeiro, João Semir, João Batista Baitello, Roseli Buzanelli Torres, Ana Maria Azevedo Tozzi, Jorge Yoshio Tamashiro e Geraldo A.D. Correia Franco pelo auxílio na identificação das espécies e a Ricardo M. Coelho pelo auxílio na conversão das classes dos solos para o sistema atual. 


\section{Referências bibliográficas}

BASNET, K. 1992. Effect of topography on the pattern of trees in tabonuco (Dacryodes excelsa) dominated rain Forest of Puerto Rico. Biotropica 24:31-42.

BERTANI, D.F., RODRIGUES, R.R., BATISTA, J.L.F. \& SHEPHERD, G.J. 2001. Análise temporal da heterogeneidade florística e estrutural em uma floresta ribeirinha. Revista Brasileira de Botânica 24:11-23.

BOTREL, R.T., OLIVEIRA FILHO, A.T., RODRIGUES, L.A. \& CURI, N. 2002. Influência do solo e topografia sobre as variações da composição florística e estrutura da comunidade arbórea-arbustiva de uma floresta estacional semidecidual em Ingaí, MG Revista Brasileira de Botânica 25:195-213.

CAVASSAN, O., CESAR, O. \& MARTINS, F.R. 1984. Fitossociologia da vegetação arbórea da Reserva Estadual de Bauru, estado de São Paulo. Revista Brasileira de Botânica 7:91-106.

CESAR, O. \& LEITÃO FILHO, H.F. 1990. Estudo florístico quantitativo de mata mesófila semidecídua na Fazenda Barreiro Rico, Município de Anhembi, SP. Revista Brasileira de Biologia 50:133-147.

CLARK, D.B. 2002. Los fatores edáficos y la distribución de las plantas. In Ecologia y conservatión de bosques neotropicais (M.R. Guariguata \& G.H. Kattan, eds.). Ediciones LUR, Cartago, p.193-221.

CLARK, D.A., CLARK, D.B., SANDOVAL M.R. \& CASTRO, C.M.V. 1995. Edaphic and human effects on landscapescale distributions of tropical rain Forest palms. Ecology 76:2581-2594.

CLARK, D.B., CLARK, D.A. \& READ, J.M. 1998. Edaphic variation and the mesoscale distribution of tree species in a neotropical rain forest. Journal of Ecology 86:101-112.

CLARK, D.B., PALMER, M.W. \& CLARK, D.A. 1999. Edaphic factors and the landscale-scale distributions of tropical rain forest trees. Ecology 80:2662-2675.

COSTA, A.A. \& ARAÚJO, G.M. 2001. Comparação da vegetação arbórea de cerradão e de cerrado na Reserva do Panga, Uberlândia, Minas Gerais. Acta Botanica Brasilica 15:63-72.

FELFILI, J.M. \& SILVA JÚNIOR, M.C. 1993 A comparative study of cerrado (sensu stricto) vegetation in Central Brazil. Journal of Tropical Ecology 9:277-289.

FELFILI, J.M., SILVA JÚNIOR, M.C., FILGUEIRAS, T.S. \& NOGUEIRA, P.E. 1998. Comparison of cerrado (sensu stricto) vegetation in central Brazil. Ciência e Cultura 50:237-343.

IPT. 2000. Diagnóstico da situação atual dos Recursos Hídricos e estabelecimento de diretrizes técnicas para elaboração do Plano da Bacia Hidrográfica do rio Pardo - Relatório Zero, Instituto de Pesquisas Tecnológicas, São Paulo, SP (http://www.sigrh.sp.gov.br).
IVANAUSKAS, N.M., RODRIGUES, R.R. \& G NAVE, A. 1997. Aspectos ecológicos de um trecho de floresta de brejo em Itatinga, SP: florística, fitossociologia e seletividade das espécies. Revista Brasileira de Botânica 20:139-153.

JOHNSTON, M.H. 1992. Soil-vegetation relationships in a tabonuco forest community in the Luquillo Mountains of Puerto Rico. Journal of Tropical Ecology 8:253-263.

JOLY, C.A. 1991. Flooding tolerance in tropical forest trees. In Plant life under oxygen deprivation: ecology, physiology and biochemestry (M.B. Jackson, D.D. Davies \& H. Lambers, eds.). SBP Academic Publishing, The Hague, p.23-34.

KOTCHETKOFF-HENRIQUES, O. 2003. Caracterização da vegetação natural em Ribeirão Preto, SP - Bases para conservação. Tese de doutoramento, Faculdade de Filosofia, Ciências e Letras de Ribeirão Preto-USP, Ribeirão Preto.

KRONKA, F.J.N., NALON, M.A., MATSUKUMA, C.K., PAVÃO, M., GUILLAUMON, J.R., CAVALLI, A.C., GIANNOTTI, E., YWANE, M.S.S.I., LIMA, L.M.P.R., MONTES, J., CALI, I.H.D. \& HAACK, P.G. 1998. Áreas de domínio de cerrado no Estado de São Paulo. Secretaria do Meio Ambiente, São Paulo.

LEITÃO FILHO, H.F. 1982. Aspectos taxonômicos das florestas do estado de São Paulo. Silvicultura em São Paulo 16A:197-206.

LEITÃO FILHO, H.F. 1987. Considerações sobre a florística de florestas tropicais e sub-tropicais do Brasil. Revista do IPEF 35:41-46.

MARTINS, F.R. 1991. Estrutura de uma floresta mesófila. Editora Unicamp, Campinas.

MCCUNE, B. \& MEFFORD, M.J. 1999. PC-ORD - Multivariate analysis of ecological data, Version 4. MjM Software Design, Gleneden Beach.

METZGER, J.P. 1999. Estrutura da paisagem e fragmentação: análise bibliográfica. Anais da Academia Brasileira de Ciências 71:445-463.

METZGER, J.P., GOLDENBERG, R. \& BERNACCI, L.C. 1998. Diversidade e estrutura de fragmentos de mata de várzea e de mata mesófila semidecídua submontana do rio Jacaré-Pepira (SP). Revista Brasileira de Botânica 21:321-330.

NEWBERY, D.M. \& PROCTOR, J. 1984. Ecological studies in four contrasting lowland rain forests ind Gunung Mulu National Park, Sarawak. Journal of Ecology 72:475-493.

OLIVEIRA, J.B. 1999. Solos do Estado de São Paulo: descrição das classes registradas no mapa pedológico. Boletim científico no 45, Instituto Agronômico de Campinas, Campinas.

OLIVEIRA, J.B. \& PRADO, H. 1983. Levantamento pedológico semi-detalhado do Estado de São Paulo Quadrícula de Ribeirão Preto, escala 1:100.000. Convênio Embrapa - Secretaria de Agricultura e Abastecimento do estado de São Paulo, Coordenadoria da Pesquisa Agropecuária e Instituto de Agronomia - Seção de Pedologia, Campinas. 
OLIVEIRA FILHO, A. \& RATTER, J.A. 2000. Padrões florísticos das matas ciliares da região do cerrado e a evolução das paisagens do Brasil Central durante o Quaternário Tardio. In Matas ciliares: conservação e recuperação (R.R. Rodrigues \& H.F.Leitão Filho, eds.). Edusp, São Paulo, p.73-89.

OLIVEIRA FILHO, A.T. \& RATTER, J.A. 2002. Vegetation physiognomies and woody flora of the cerrado biome. In The cerrados of Brazil (P.S. Oliveira \& R.J. Marquis, eds.). Columbia University Press, New York, p.91-120.

OLIVEIRA FILHO, A.T., VILELA, E.A., CARVALHO, D.A. \& GAVILANES, M.L. 1994a. Effects of soils and topography on the distribution of tree especies in a tropical riverine forest in south-eastern Brazil. Journal of Tropical Ecology 10:483-508.

OLIVEIRA FILHO, A.T., VILELA, E.A., CARVALHO, D.A. \& GAVILANES, M.L. 1994b. Differentiation of streamside and upland vegetation in an area of montane semidecidous forest in southeartern Brazil. Flora 189:287-305.

RATTER, J.A., BRIDGEWATER, S. \& RIBEIRO, J.F. 2001. Espécies lenhosas da fitofisionomia cerrado sentido amplo de 170 localidades do Bioma Cerrado. Boletim do Herbário Ezechias Paulo Heringer 7:5-112.

RIBEIRO, J.F. \& WALTER, B.M.T. 1998. Fitofisionomias do bioma cerrado. In Cerrado: ambiente e flora (S.M. Sano \& S.P. Almeida, eds.). Embrapa, CPAC, Planaltina, DF. p.89-164.

RODRIGUES, R.R., GANDOLFI, S. 1996. Recomposição de florestas nativas: princípios gerais e subsídios para uma definição metodológica. Revista Brasileira de Horticultura Ornamental 2:4-15.
SALIS, S.M., SHEPHERD, G.J. \& JOLY, C.A. 1995. Floristic comparison of mesophytic semideciduous forests of the interior of the state of São Paulo, Southeast Brazil. Vegetatio 119:155-164.

SOARES, J.J., SILVA, D.W. \& LIMA, M.I.S. 2003. Current state and projection of the probable original vegetation of the São Carlos region of São Paulo State, Brazil. Brazilian Journal of Biology 63:527-536.

SOKAL, R.R. \& ROHLF, F.J. 1995. Biometry: the principles and practice of statistics in biological research. $3^{\text {rd }}$ ed. W.H. Freeman, New York.

SWAINE, M.D. 1996. Rainfall and soil fertility as factors limiting forest species distributions in Ghana. Journal of Ecology 84:419-428.

TER BRAAK, C.J.F. 1995 Ordination. In Data analysis in community and ladscape ecology (R.H.G. Jongman, C.J.F. ter Braak \& O.F.R. van Tongeren, eds.). Cambridge University Press, Cambridge, p.91-173.

TORRES, R.B., MATTHES, L.A.F. \& RODRIGUES, R.R. 1994. Florística e fitossociologia do componente arbóreo de mata de brejo em Campinas, SP. Revista Brasileira de Botânica 17:189-194.

TORRES, R.B., MARTINS, F.R. \& KINOSHITA, L.S. 1997. Climate, soil and tree flora relationships in forests in the state of São Paulo, southeastern Brasil. Revista Brasileira de Botânica 20:41-50.

TURNER, M.G. 1989. Landscape ecology: the effect of pattern on process. Annual Review of Ecology and Systematics 20:171-197.

TURNER, I.A. \& CORLETT, R.T. 1996. The conservation value of small, isolated fragments of lowland tropical rain forest. Trends in Ecology and Evolution 11:330-333.

VICTOR, M.A.M. 1975. A devastação florestal. Sociedade Brasileira de Silvicultura, São Paulo. 